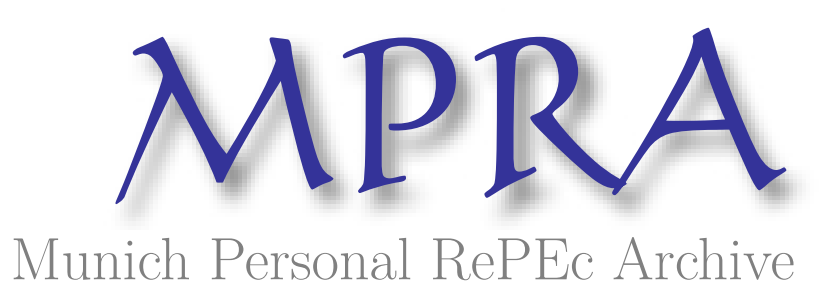

\title{
Knowledge, Preferences and Shocks in Portfolio Analysis
}

Steinbacher, Matjaz

2009

Online at https://mpra.ub.uni-muenchen.de/13567/

MPRA Paper No. 13567, posted 22 Feb 2009 02:27 UTC 


\title{
KNOWLEDGE, PREFERENCES AND SHOCKS IN PORTFOLIO ANALYSIS
}

\author{
Matjaz Steinbacher \\ Steinbacher.si \\ Financial analyst and advisor \\ Prvomajska ulica 7 \\ SI - 2310 Slovenska Bistrica, Slovenia \\ e-mail: matjaz@steinbacher.si \\ Phone: +38641960928
}

\begin{abstract}
We simulate social network games of a portfolio selection to analyze how knowledge, preferences of agents and their level of omniscience affect their decision-making. The key feature of the paper is that preferences and the level of omniscience of agents very much determine the ways agents make their decision. While omniscient agents respond very rapidly to the changing market conditions, non-omniscient agents are more resistant to such changes. By introducing one-time shock, we found that its efficiency depends on the level of omniscience of agents, with much stronger efficiency under omniscient agents.
\end{abstract}

Keywords: small world networks, stochastic finance, portfolio analysis, market shocks, non-omniscience. 


\section{Introduction}

Developments on financial markets can generally be characterized by the following: uncertainty, seeking for information, and social networks, while key elements are an individual with his knowledge, preferences and other personal characteristics, and information about the assets. Individuals on the markets are non-omniscient agents in the sense that they possess only "small bits of incomplete and frequently contradictory knowledge" (Hayek 1945, 519). ${ }^{1}$ Such Hayekian individuals seek information, cooperate and make social networks, learn, choose, take risks, compete, imitate and trade with each other. They improve their knowledge through public and private data banks, learning from their experiences and through communication processes in the social network, which induce herd behavior. Herd behavior has been documented on financial markets (Lux 1995; Cont and Bouchaud 2000; Shiller 2002; Bikhchandani et al. 1998). Different knowledge, preferences and other specific characteristics of agents mean that despite identical data people make different expectations (Kahneman and Tversky 1979; Hirshleifer 2002). This means that despite agents are prone to copying more profitable strategies, tradeoff between the efficiency and complexity of strategies and the desire to take as simple strategies as possible might lead them to take less profitable ones, as well (Rubinstein 1998).

Very often phenomena on the markets are shocks that are especially connected with stock bubbles and crashes (Abreu and Brunnermeier 2003). As regards shocks, it is important how fast agents on markets perceive them, if they perceive them, how persistent they are and how effective they are. We tackle these questions through simulations using different levels of omniscience and attitudes towards risk of agents.

\footnotetext{
${ }^{1}$ We avoid using terms rational and irrational behavior and consider them inappropriate, as the ultimate goal of individuals is always to satisfy their goals (Mises 1996, Rand 1964). If A is preferred to B and B to C, logically A should be preferred to C. But if C is preferred to A, this regards the fact that two acts of an individual can never be synchronous as value judgments are not immutable (Mises 1996, 103).
} 
In the paper, we model and simulate such games of a portfolio analysis on real data, with agents using social networks and choosing between stocks of two bank corporations, Citigroup (NYSE: C) and CreditSuisse (NYSE: CS), or the portfolio of the two. In a general framework of Chapter 2, we put down the model, which is continued with the simulation results in Chapter 3. Final Chapter gives some concluding remarks.

\section{General framework}

\subsection{The model}

There are $A=(1,2, \ldots, 1000)$ infinitely lived agents, distributed on the lattice and connected in the small world network (Watts and Strogatz 1998; Wasserman and Faust 1994). The network $g=(V, E)$ is a set of vertices $V=\left\{v_{1}, v_{2}, \ldots, v_{1000}\right\}$, representing agents, and edges $E=\left\{e_{1}, e_{2}, \ldots, e_{n}\right\}$, representing their pairwise relations. If two agents are connected, we denote $i j \in g$, while $i j \notin g$ represents two unconnected vertices. Using adjacency matrix, $i j=1$ if $i j \in g$ and $i j=0$ if $i j \notin g$. We use undirected graph, where edges are unordered pairs of vertices, thus if $i j=1 \Leftrightarrow j i=1$. In a small world network, people have many local and some global connections with others, which we get by rewiring some of the connections (Figure 1).

Figure 1: Small world network 


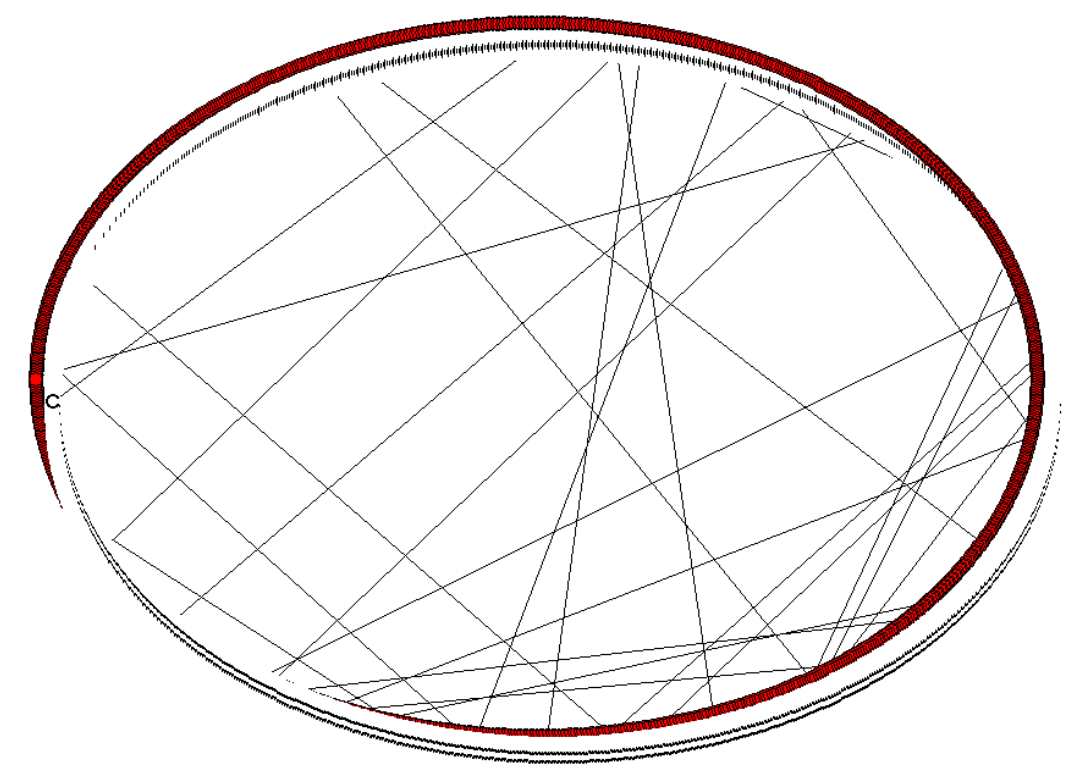

In the network, a degree of an agent is the number of agents to which one is connected. It is denoted $k\left(A_{i}\right)$. The average degree of agents in the network equals $\bar{k}_{i}(g)=6$, and the probability that a connection from an agent $A_{i}$ is rewired to the randomly chosen agent $A_{j}$ in the network equals $p=0.01$. The network remains unchanged once connections are rewired. There are no isolated agents in the network. Distance in the network between the two agents is represented as the shortest path between them, and diameter represents the longest distance in the network. In one representation of a network, the average distance among all pairs of agents is $\bar{d}\left(A_{i}, A_{j}\right)=12.818$, while the diameter equals $D=\max \left(d\left(A_{i}, A_{j}\right)\right)=28$.

According to their initial preferences, agents are split into two groups; the first consists of those who prefer Citigroup stocks, and the second of those who prefer CreditSuisse stocks. We denote $0 \leq u \leq 1$ the share of agents who prefer stocks of CreditSuisse, and $(1-u)$ a share of agents preferring stocks of Citigroup. Agents from both groups can choose between pure strategy, which means that either they opt for stocks of Citigroup or CreditSuisse or make a portfolio of the two. We denote with $C$, if agents who prefer Citigroup stocks decide for pure strategies and $C p$ if they opt for a portfolio. Contrary, we denote $C S$ when agents who prefer CreditSuisse stocks decide for pure strategies and CSp if they opt for a 
portfolio. In either case, portfolio is selected from the part of stocks one prefers, $0 \leq p i \leq 1$, while remainder $(1-p i)$ represents stocks of the other company. Agents accumulate their wealth in time according to the strategy they choose, while they can change between the strategies in every period during the game.

$$
\begin{aligned}
& W_{t+1}\left(A_{C}\right)=W_{t}\left(A_{C}\right) \cdot[1+C r] \\
& W_{t+1}\left(A_{C p}\right)=W_{t}\left(A_{C p}\right) \cdot[1+C r \cdot p i+C S r \cdot(1-p i)] \\
& W_{t+1}\left(A_{C S p}\right)=W_{t}\left(A_{C S p}\right) \cdot[1+C S r \cdot p i+C r \cdot(1-p i)] \\
& W_{t+1}\left(A_{C S}\right)=W_{t}\left(A_{C S}\right) \cdot[1+C S r]
\end{aligned}
$$

$W_{t+1}(\bullet)$ and $W_{t}(\bullet)$ represent wealth of an agent in time $t$ and $t+1$, while $(\bullet)$ denotes the strategy played by an agent in time. Returns of stocks, denoted $\mathrm{Cr}$ and $C S r$, are exogenous to the agents and agents cannot foresee them, neither do they know the system how prices change in time. $t=(1,2, \ldots, T)$.

We also introduce the level of non-omniscience of agents denoted $0 \leq \kappa \leq 1$. It is defined through Fermi logistic probability function (Szabó and Töke 1998) as

$$
\wp=\left[1+\exp \left[\left(W\left(A_{i}\right)-W\left(A_{j}\right)\right) / \kappa\right]\right]^{-1}
$$

This means that in every time period $t$ an agent $A_{i}$ chooses one of the agents to which he his directly connected, $A_{j}$, and compares his payoff, $W\left(A_{i}\right)$, to the payoff of selected agent, $W\left(A_{j}\right)$. It depends upon the level of coefficient $\kappa$ which strategy agent $A_{i}$ will adopt. For $\kappa=0$, he always adopts the strategy that gives higher outcome. We denote such agent omniscient agent. Higher the value of $\kappa$ and smaller the difference between the two payoffs, more likely it is that an agent will not choose the strategy with higher payoff. Such agent is denoted nonomniscient. Contrary, lower the value of a coefficient $\kappa$ and bigger the difference between the two payoffs, more likely it is that an agent will choose the strategy with higher payoff. This goes in line with Rubinstein's tradeoff. In simulations, 
we use $\kappa=0.001$ for omniscient agent and $\kappa=1.0$ for non-omniscient agent. Once agents lose a link to a particular strategy, they are not able to get it back in future and cannot choose such strategy again.

Finally, we put one-time shock into the stock of Citigroup in time $t=2$ by lowering the return of a stock by $500 \mathrm{bps}$, ceteris paribus. Thus, instead of a positive return of 3.165 percentage points we apply a loss of 1.835 percentage points.

\subsection{Data}

We used data from finance.yahoo.com portal. Data refer to adjusted closed prices of both stocks from 21.1.1999 until 19.11.2008. An adjusted closed price is a price adjusted for splits and dividends. In order to use the same time-period for both stocks, we omit adjusted closed prices for the stock for a time units if the other stock was inactive on that day. In each game, we have $T=2.457$ iterations. Adjusted close price for Citigroup and CreditSuisse are plotted in Figures 2a, b, c.

Figure 2a: Daily returns of CreditSuisse

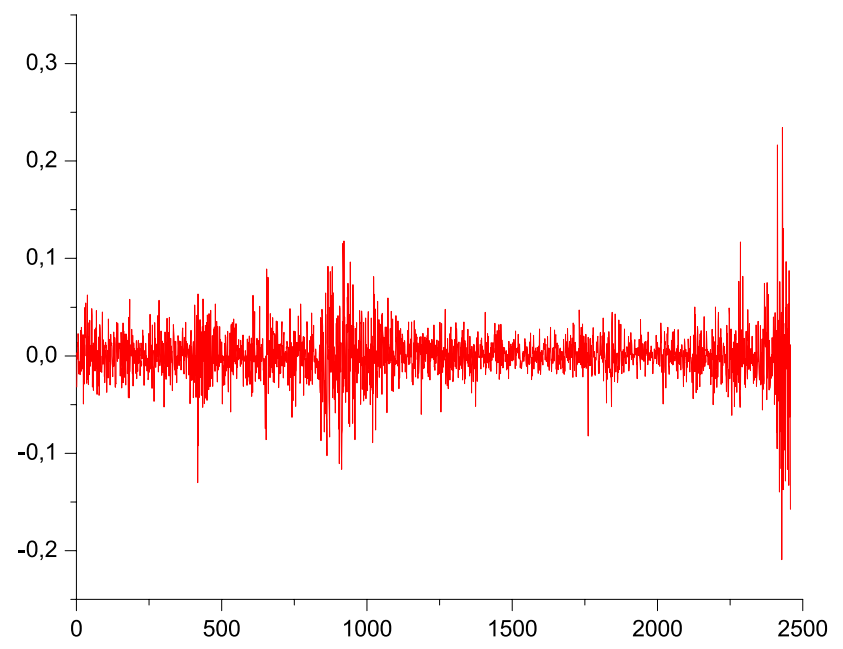

Figure 2b: Daily returns of Citigroup 


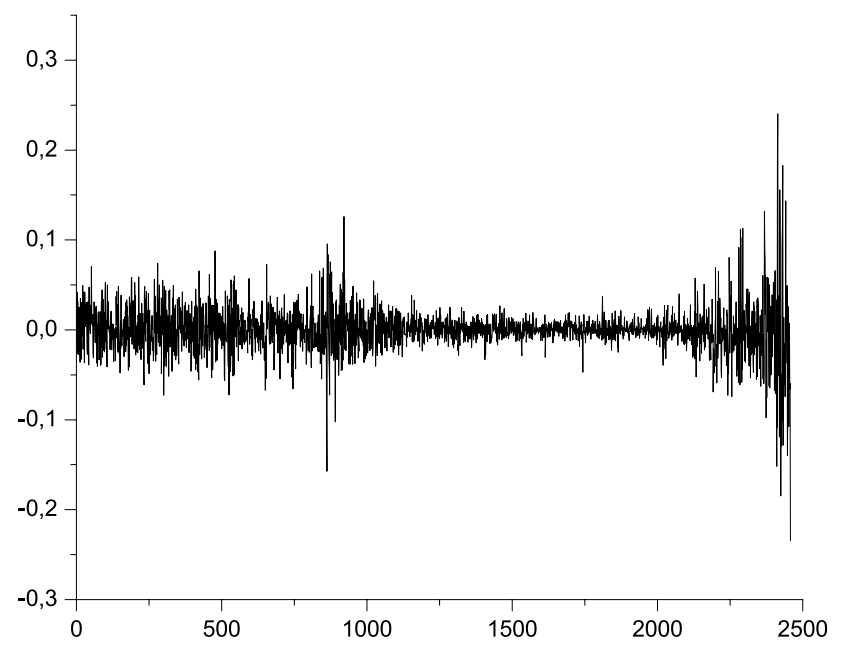

Figure 2c: Daily returns of CreditSuisse and Citigroup

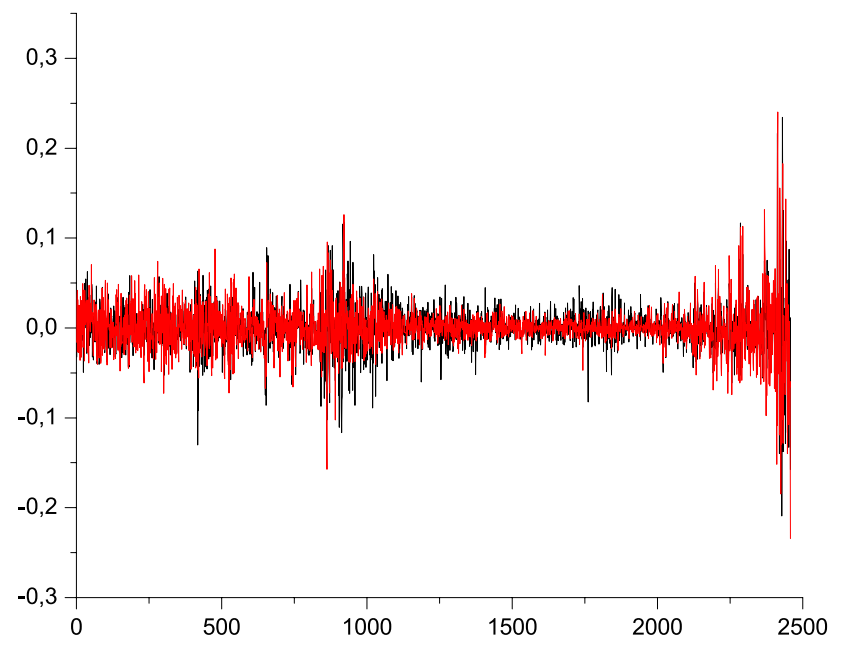

\section{Simulation results}

\subsection{Omniscient agents}

We first simulate games with omniscient agents. Sizes of the step on both variables are 0.1 throughout the sample spaces $0 \leq u, p i \leq 1$. The averages of 15 realizations of games are represented in Figures 3. 
Figure 3a: Omniscient agents who choose $C$

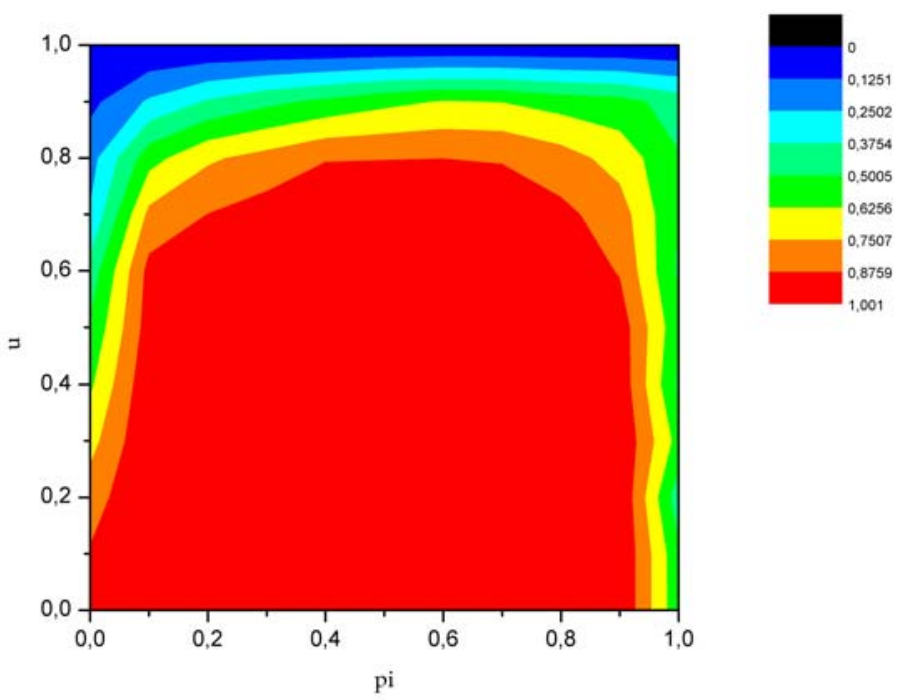

Figure 3b: Omniscient agents who choose $C p$

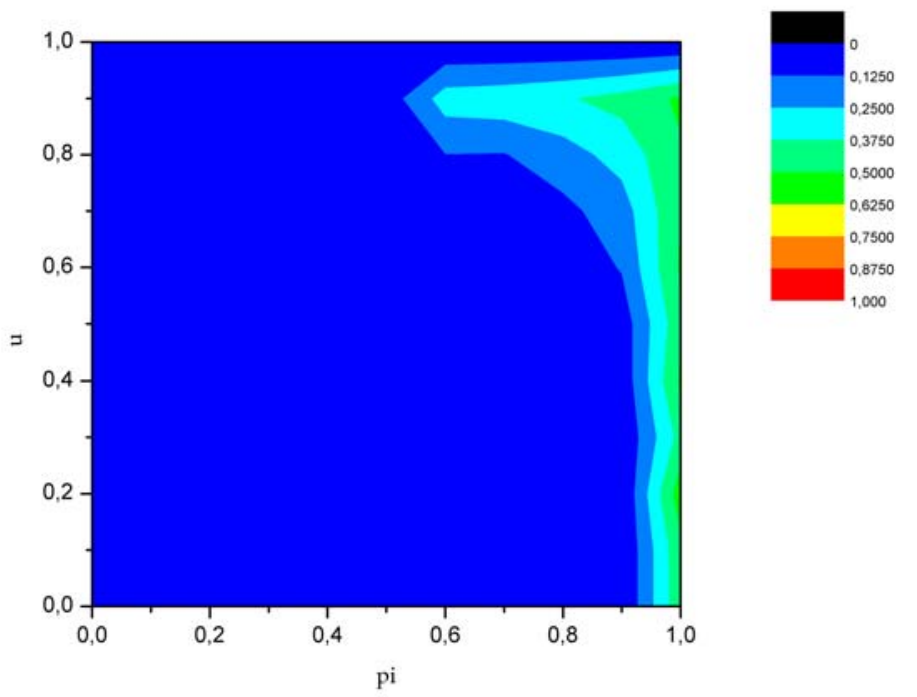

Figure 3c: Omniscient agents who choose $C S p$ 


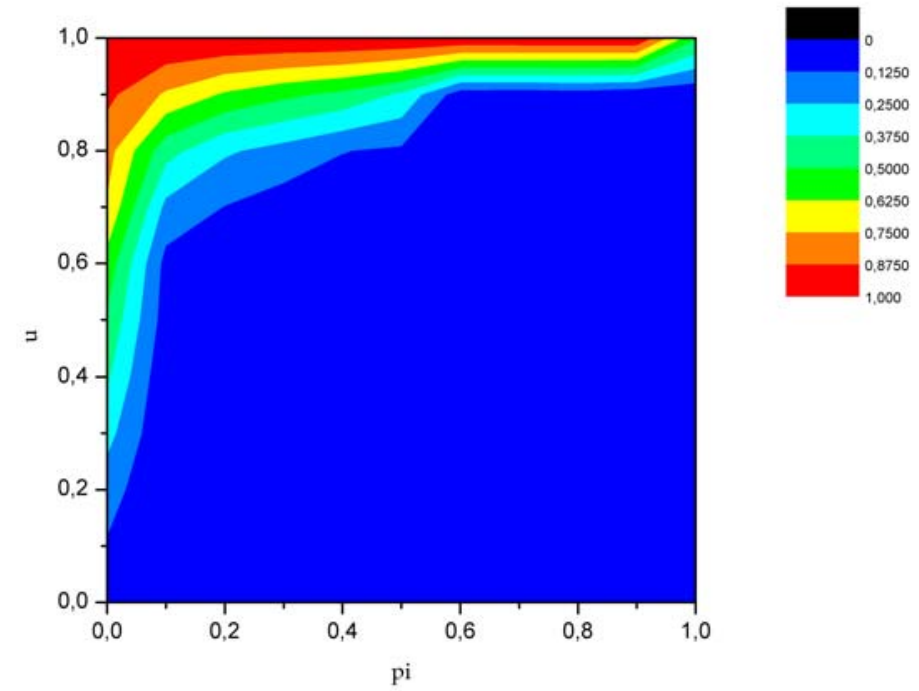

Figure 3d: Omniscient agents who choose $C S$

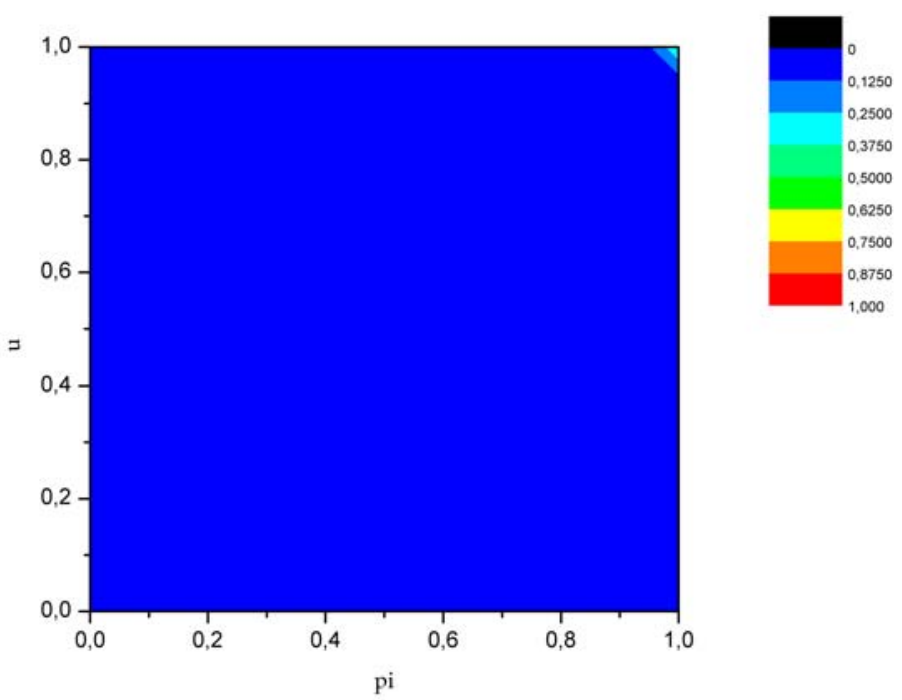

Color-palettes in the figures represent shares of agents who choose for an individual strategy in the final stage of the game.

Figures reveal that the most relevant factor of decision-making of omniscient agents are returns of stocks. Initial preferences of agents, measured through coefficient $u$, become significant only around the limit cases, when agents prefer portfolio. 
We now simulate games with a shock of $500 \mathrm{bps}$ in $t=2$ included and present results in Figures 4.

Figure 4a: Omniscient agents under shock who choose $C$

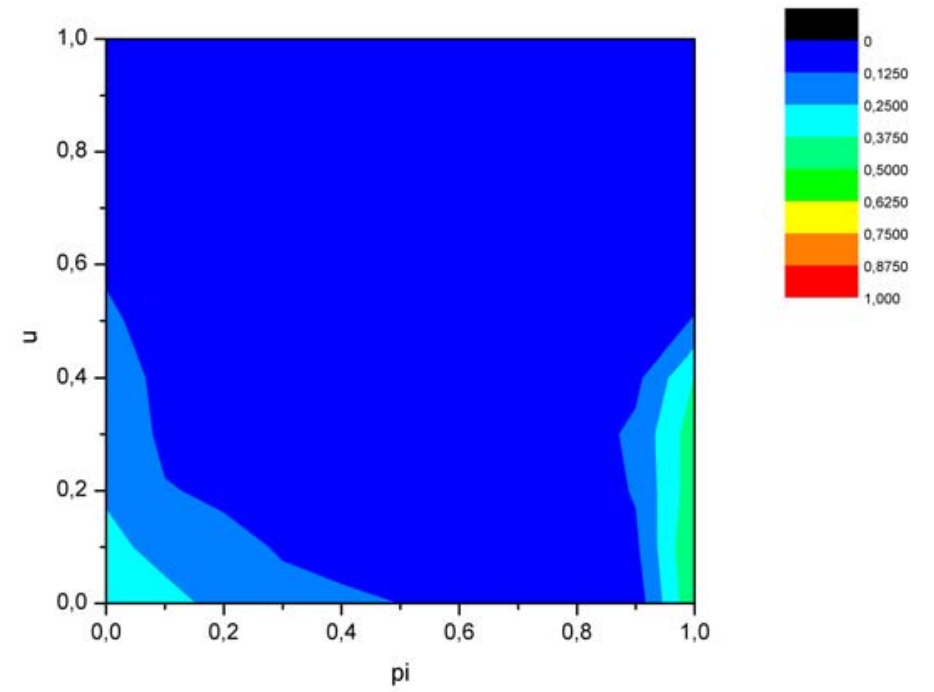

Figure 4b: Omniscient agents under shock who choose $C p$

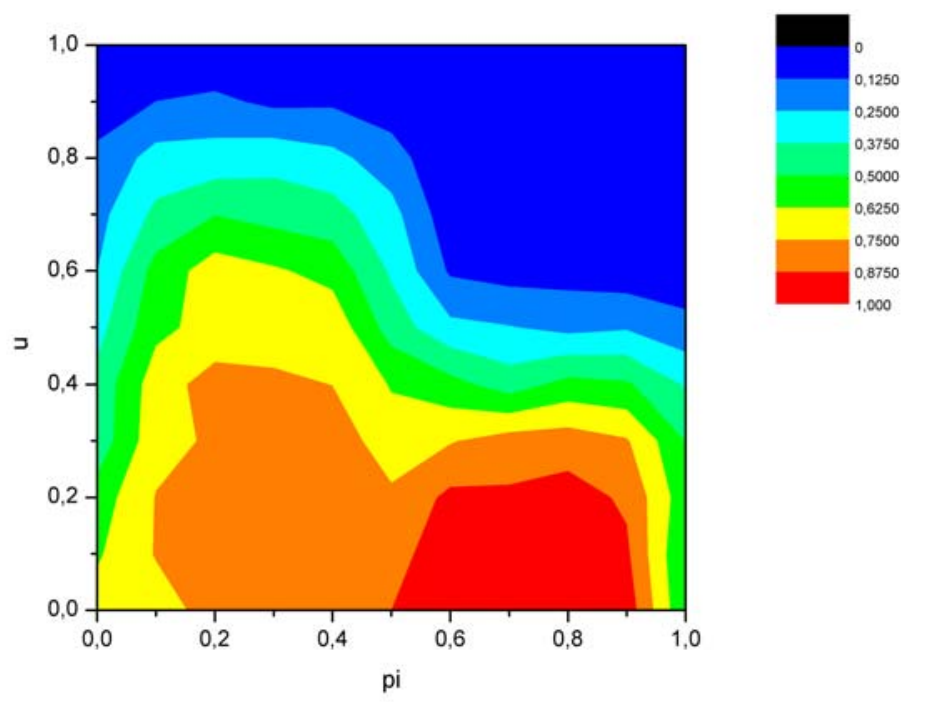

Figure 4c: Omniscient agents under shock who choose CSp 


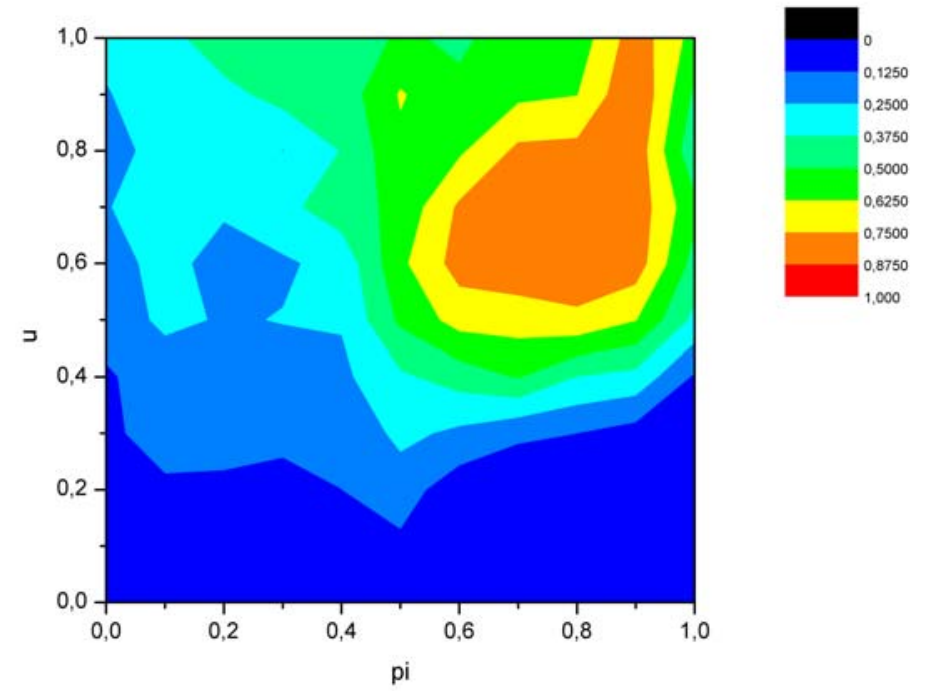

Figure 4d: Omniscient agents under shock who choose $C S$

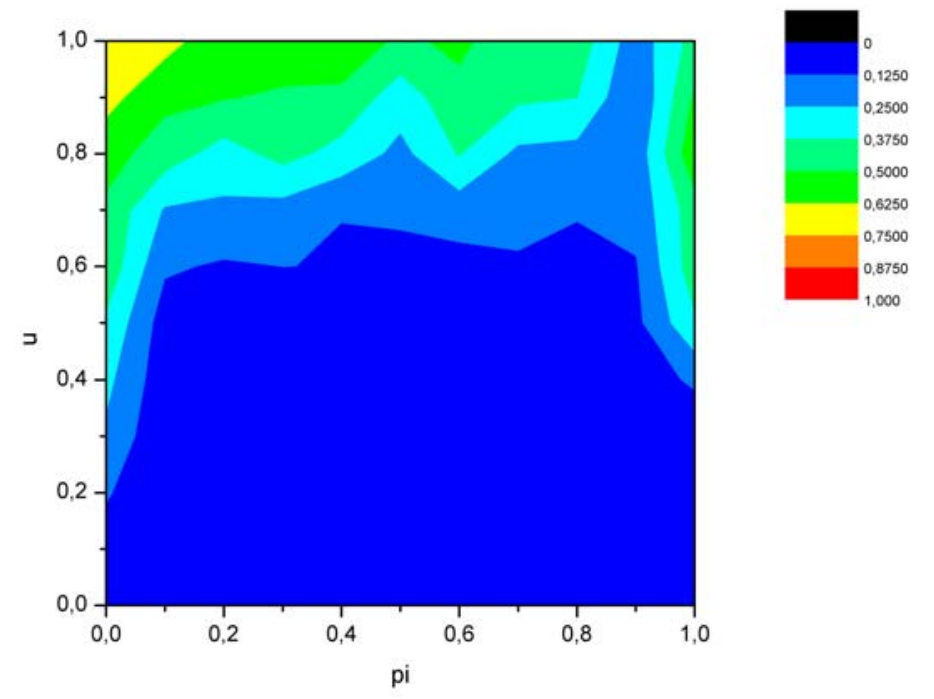

A comparison of Figures 4 to Figures 3 reveals that a shock to the Citigroup stock rapidly changes the behavior of agents. Due to a shock, agents turn away of pure strategies of having Citigroup stock and in a much greater extend opt for a diversification or even for playing pure CreditSuisse strategies. This is due the fact that the difference in returns of the two stocks is very small in time, which makes shock, despite only one-time shock, very significant in relative terms.

We now turn to some individual games under different initial values of $u$ and plot their entire developments. 


$$
u=0.5
$$

We first choose $u=0.5$ and $p i=0.3$ and compare games without a shock, plotted in Figures 5a, b, with the games with included shock in Figures 6a, b. $u$ is changing in time, while $p i$ is constant. $C$ in figures represent the share of agents that choose Citigroup, $C p$ represent the share of agents who prefer Citigroup stocks and choose for a portfolio. Similarly, $C S$ and $C S p$ represent shares of agents who prefer CreditSuisse stocks and opt for pure strategies or portfolio.

Figure 5a: Game with omniscient agents

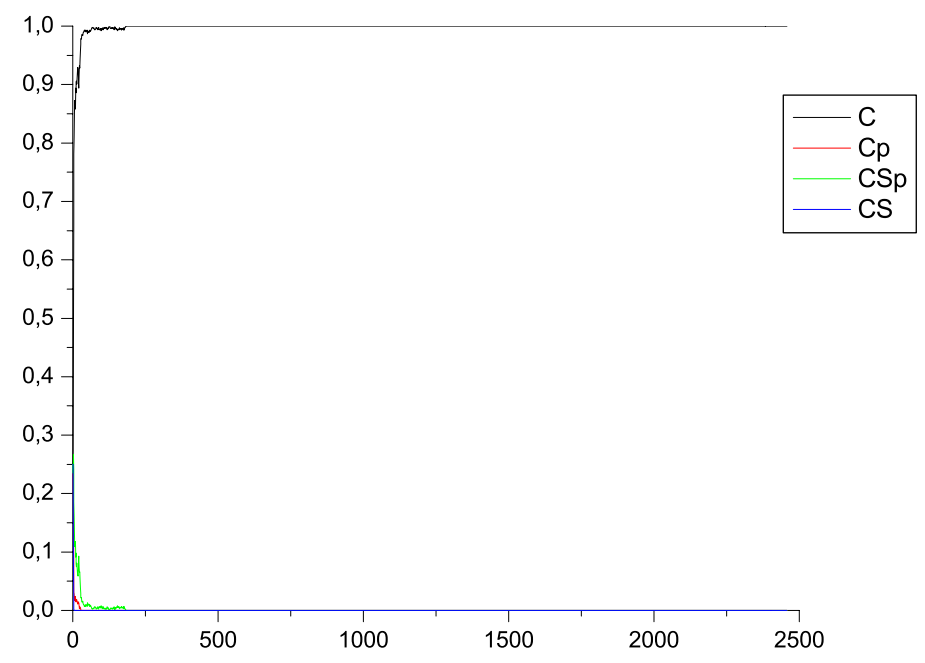

Figure 5b: Game with omniscient agents 


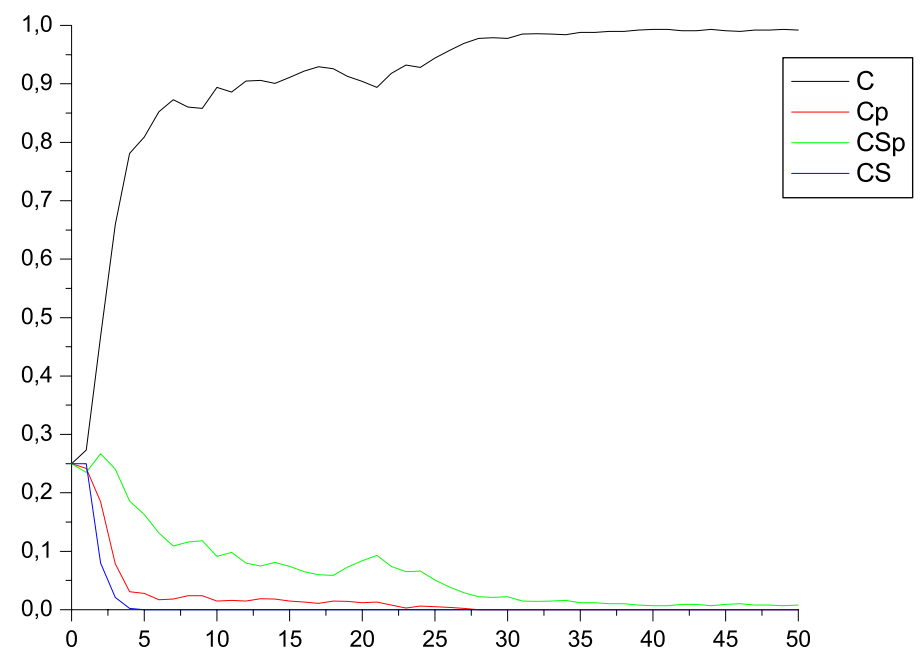

In a no-shock game, possession of Citigroup stocks is a dominant strategy played by omniscient agents. We see from the figure that agents come close to a unanimous solution in less then fifty time intervals.

Figure 6a: Game with a shock

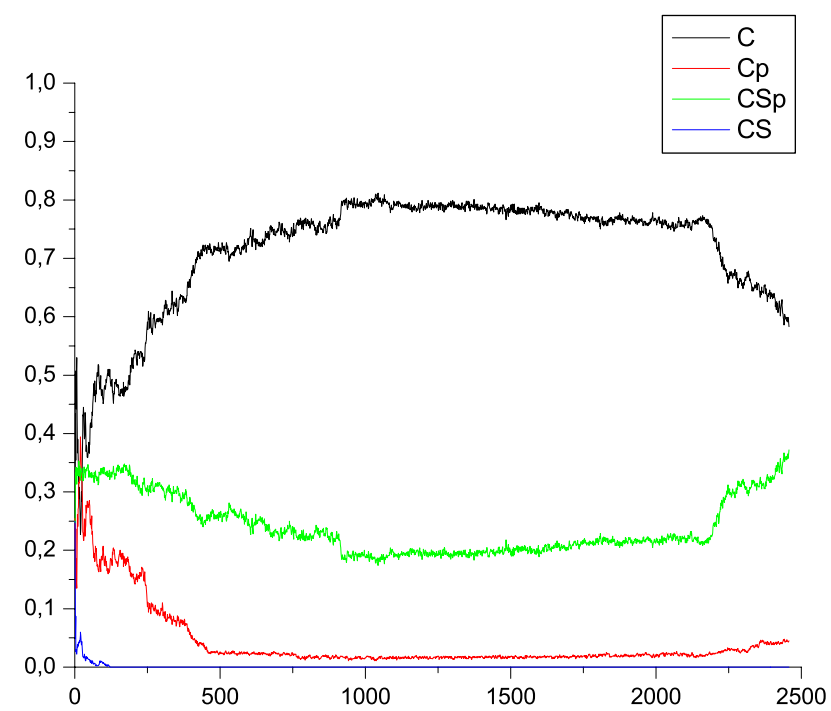

Figure 6b: Game with a shock 


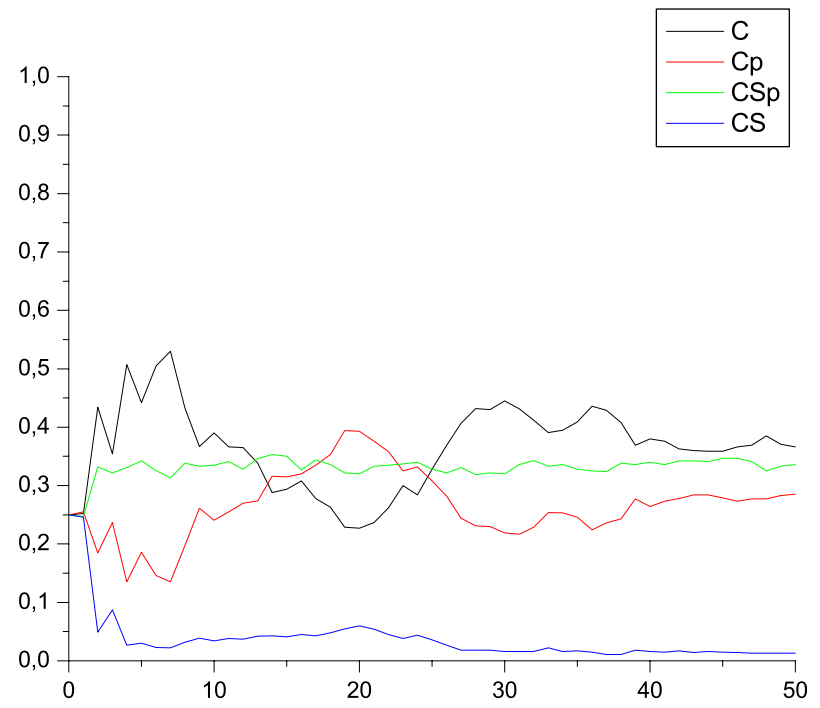

Comparing the two figures reveals that one-time shock of $500 \mathrm{bps}$ on Citigroup stock changed the behavior of agents and the course of the game drastically. Now, none of the strategies is dominant in the long run. Table 1 presents some details on early intervals. Column 1 represents time interval, columns 2-3 represent daily returns of Citigroup and CreditSuisse stocks, columns 4-7 represent shares of agents playing each strategy in a no-shock game, while columns 8-11 represent shares of agents playing each strategy in a game with a shock. We presence of a shock is denoted with bold in the third line of the second column. The coefficient of the return under the shock needs to be reduced by 500 bps to 0.9817 .

Table 1: Games with no shock and with a shock

$\begin{array}{ccccccccccc}\mathrm{t} & \mathrm{Cr} & \mathrm{CSr} & \mathrm{C} & \mathrm{Cp} & \mathrm{CSp} & \mathrm{CS} & \mathrm{C}_{-} \mathrm{s} & \mathrm{Cp} \_\mathrm{CSp} \text { _s } & \text { CS_S } \\ 1 & 0.9842 & 0.9679 & 0.25 & 0.25 & 0.25 & 0.25 & 0.25 & 0.25 & 0.25 & 0.25 \\ 2 & \mathbf{1 . 0 3 1 7} & 1.0032 & 0.273 & 0.242 & 0.235 & 0.25 & 0.252 & 0.255 & 0.247 & 0.246 \\ 3 & 1.0420 & 0.9968 & 0.468 & 0.185 & 0.267 & 0.08 & 0.434 & 0.185 & 0.332 & 0.049 \\ 4 & 0.9731 & 1.0132 & 0.659 & 0.079 & 0.241 & 0.021 & 0.354 & 0.237 & 0.322 & 0.087 \\ 5 & 1.0313 & 1.0099 & 0.781 & 0.031 & 0.186 & 0.002 & 0.507 & 0.135 & 0.331 & 0.027 \\ 6 & 1.0098 & 1.0227 & 0.809 & 0.028 & 0.163 & 0 & 0.442 & 0.186 & 0.342 & 0.03 \\ 7 & 0.9725 & 1.0157 & 0.852 & 0.017 & 0.131 & 0 & 0.505 & 0.146 & 0.326 & 0.023 \\ 8 & 0.9733 & 0.9812 & 0.873 & 0.018 & 0.109 & 0 & 0.53 & 0.135 & 0.313 & 0.022\end{array}$




$\begin{array}{ccccccccccc}9 & 1.0253 & 0.9938 & 0.86 & 0.024 & 0.116 & 0 & 0.432 & 0.198 & 0.338 & 0.032 \\ 10 & 0.9769 & 0.9935 & 0.858 & 0.024 & 0.118 & 0 & 0.367 & 0.261 & 0.333 & 0.039 \\ 11 & 0.9952 & 0.9937 & 0.894 & 0.015 & 0.091 & 0 & 0.39 & 0.241 & 0.335 & 0.034 \\ 12 & 0.9930 & 0.9934 & 0.886 & 0.016 & 0.098 & 0 & 0.366 & 0.255 & 0.341 & 0.038 \\ 13 & 0.9641 & 0.9807 & 0.905 & 0.015 & 0.08 & 0 & 0.365 & 0.27 & 0.328 & 0.037 \\ 14 & 1.0350 & 1.0065 & 0.906 & 0.019 & 0.075 & 0 & 0.338 & 0.274 & 0.346 & 0.042 \\ 15 & 1.0235 & 1.0263 & 0.901 & 0.018 & 0.081 & 0 & 0.288 & 0.316 & 0.353 & 0.043 \\ 16 & 0.9675 & 0.9840 & 0.911 & 0.015 & 0.074 & 0 & 0.294 & 0.315 & 0.35 & 0.041 \\ 17 & 1.0303 & 1.0293 & 0.922 & 0.013 & 0.065 & 0 & 0.308 & 0.32 & 0.327 & 0.045 \\ 18 & 0.9925 & 1.0204 & 0.929 & 0.011 & 0.06 & 0 & 0.278 & 0.335 & 0.344 & 0.043 \\ 19 & 0.9979 & 0.9864 & 0.926 & 0.015 & 0.059 & 0 & 0.263 & 0.353 & 0.336 & 0.048 \\ 20 & 1.0238 & 1.0061 & 0.913 & 0.014 & 0.073 & 0 & 0.229 & 0.394 & 0.322 & 0.055 \\ 21 & 1.0232 & 0.9875 & 0.904 & 0.012 & 0.084 & 0 & 0.227 & 0.393 & 0.32 & 0.06 \\ 22 & 1.0495 & 1.0034 & 0.894 & 0.013 & 0.093 & 0 & 0.237 & 0.376 & 0.333 & 0.054 \\ 23 & 0.9784 & 1.0219 & 0.918 & 0.008 & 0.074 & 0 & 0.262 & 0.358 & 0.335 & 0.045 \\ 24 & 0.9945 & 0.9506 & 0.932 & 0.003 & 0.065 & 0 & 0.3 & 0.325 & 0.337 & 0.038 \\ 25 & 1.0378 & 1.0067 & 0.928 & 0.006 & 0.066 & 0 & 0.284 & 0.332 & 0.34 & 0.044 \\ 26 & 1.0423 & 1.0098 & 0.944 & 0.005 & 0.051 & 0 & 0.328 & 0.308 & 0.328 & 0.036 \\ 27 & 0.9632 & 0.9710 & 0.957 & 0.004 & 0.039 & 0 & 0.369 & 0.282 & 0.322 & 0.027 \\ 28 & 0.9811 & 0.9968 & 0.969 & 0.002 & 0.029 & 0 & 0.407 & 0.244 & 0.331 & 0.018 \\ 29 & 1.0420 & 1.0496 & 0.978 & 0 & 0.022 & 0 & 0.432 & 0.231 & 0.319 & 0.018 \\ 30 & 1.0242 & 1.0187 & 0.979 & 0 & 0.021 & 0 & 0.43 & 0.23 & 0.322 & 0.018 \\ 31 & 1.0037 & 1.0187 & 0.978 & 0 & 0.022 & 0 & 0.445 & 0.219 & 0.32 & 0.016 \\ 32 & 1.0083 & 1.0544 & 0.985 & 0 & 0.015 & 0 & 0.431 & 0.217 & 0.336 & 0.016\end{array}$

It is seen that agents react to a shock with one time-interval lag and that its consequences last throughout the game.

$$
u=0.8
$$


We now increase initial share of agents preferring stocks of CreditSuisse, thus $u=0.8$. The value of $p i=0.3$ and does not change in time. A simulation of the game is plotted in Figure 7a, b.

Figure 7a: Game with omniscient agents

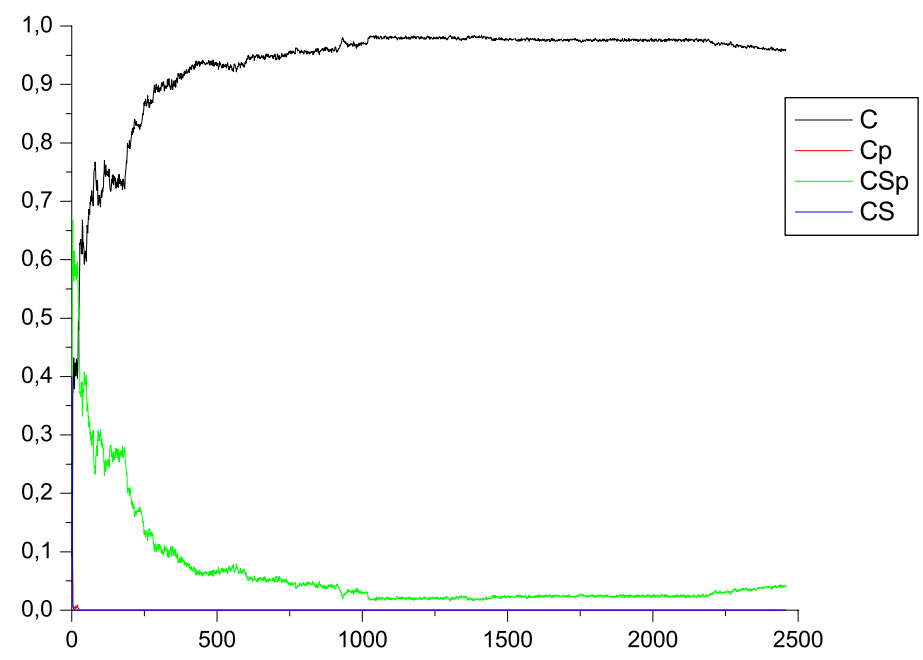

Figure 7b: Game with omniscient agents

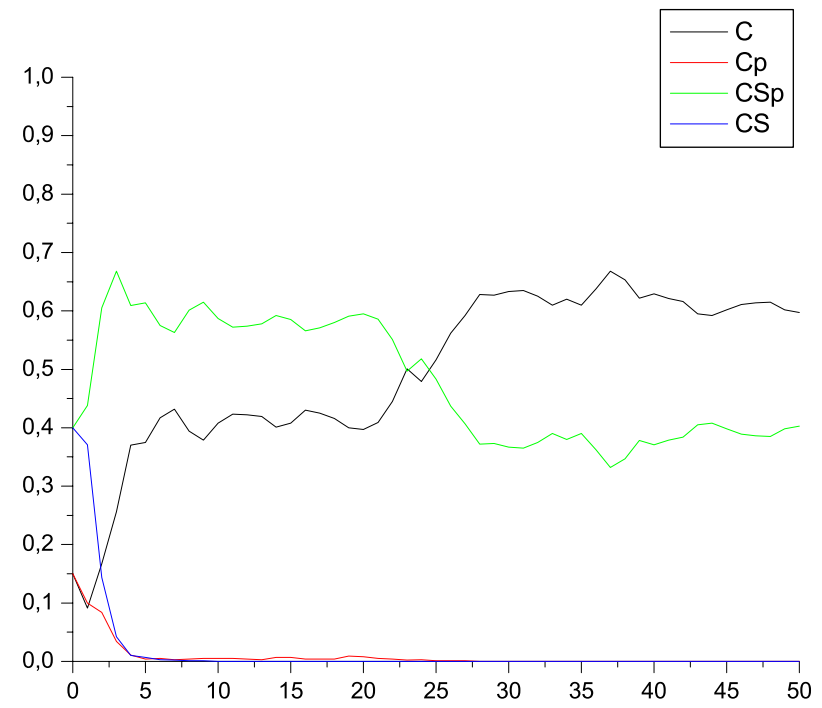

Under new circumstances, omniscient agents are no longer able to define a dominant strategy despite vast majority opt for Citigroup, attaching importance to 
the information sources and the quality of ties in the social network. The better and more heterogeneous ties one has, better solutions such agent is able to adopt.

We now put a shock into the game and plot the results in Figures $8 \mathrm{a}, \mathrm{b}$.

Figure 8a: Game with a shock

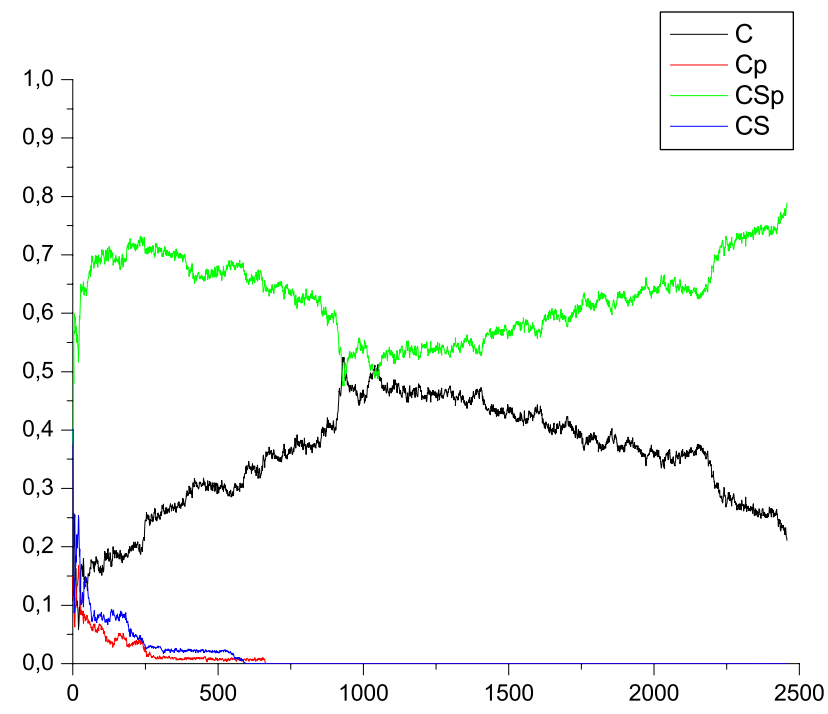

Figure 8b: Game with a shock

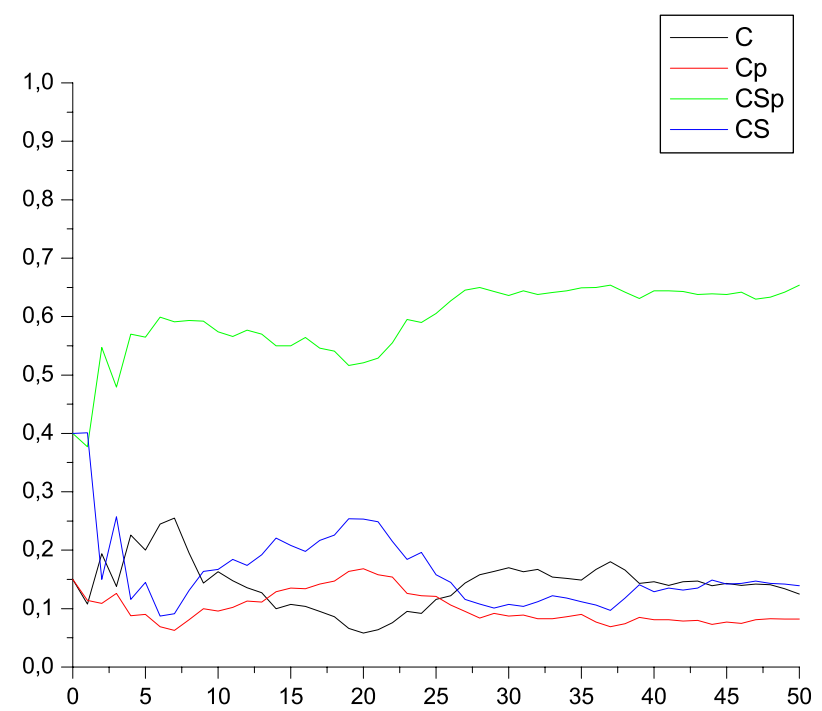


Again, we see that the shock disturbs conditions on the market significantly, for which it affects the decision-making of agents very much, while it is persistent throughout the game (see also Table 2).

Table 2: Games with no shock and with a shock

$\begin{array}{ccccccccccc}\mathrm{t} & \mathrm{Cr} & \mathrm{CSr} & \mathrm{C} & \mathrm{Cp} & \mathrm{CSp} & \mathrm{CS} & \mathrm{C} \_\mathrm{s} & \mathrm{Cp} \_\mathrm{s} & \mathrm{CSp} \mathrm{S}_{-} \mathrm{CS} \mathrm{CS}_{-} \\ 1 & 0.9842 & 0.9679 & 0.15 & 0.15 & 0.4 & 0.4 & 0.15 & 0.15 & 0.4 & 0.4 \\ 2 & \mathbf{1 . 0 3 1 7} & 1.0032 & 0.091 & 0.1 & 0.438 & 0.371 & 0.108 & 0.114 & 0.377 & 0.401 \\ 3 & 1.0420 & 0.9968 & 0.167 & 0.084 & 0.605 & 0.144 & 0.194 & 0.109 & 0.547 & 0.15 \\ 4 & 0.9731 & 1.0132 & 0.256 & 0.034 & 0.668 & 0.042 & 0.138 & 0.126 & 0.479 & 0.257 \\ 5 & 1.0313 & 1.0099 & 0.37 & 0.011 & 0.609 & 0.01 & 0.226 & 0.088 & 0.57 & 0.116 \\ 6 & 1.0098 & 1.0227 & 0.375 & 0.004 & 0.614 & 0.007 & 0.2 & 0.09 & 0.565 & 0.145 \\ 7 & 0.9725 & 1.0157 & 0.417 & 0.005 & 0.575 & 0.003 & 0.245 & 0.069 & 0.599 & 0.087 \\ 8 & 0.9733 & 0.9812 & 0.432 & 0.003 & 0.563 & 0.002 & 0.255 & 0.063 & 0.591 & 0.091 \\ 9 & 1.0253 & 0.9938 & 0.394 & 0.004 & 0.601 & 0.001 & 0.195 & 0.081 & 0.593 & 0.131 \\ 10 & 0.9769 & 0.9935 & 0.379 & 0.005 & 0.615 & 0.001 & 0.144 & 0.1 & 0.592 & 0.164 \\ 11 & 0.9952 & 0.9937 & 0.408 & 0.005 & 0.587 & 0 & 0.163 & 0.096 & 0.574 & 0.167 \\ 12 & 0.9930 & 0.9934 & 0.423 & 0.005 & 0.572 & 0 & 0.148 & 0.102 & 0.566 & 0.184 \\ 13 & 0.9641 & 0.9807 & 0.422 & 0.004 & 0.574 & 0 & 0.136 & 0.113 & 0.577 & 0.174 \\ 14 & 1.0350 & 1.0065 & 0.419 & 0.003 & 0.578 & 0 & 0.127 & 0.111 & 0.57 & 0.192 \\ 15 & 1.0235 & 1.0263 & 0.401 & 0.007 & 0.592 & 0 & 0.1 & 0.129 & 0.55 & 0.221 \\ 16 & 0.9675 & 0.9840 & 0.408 & 0.007 & 0.585 & 0 & 0.107 & 0.135 & 0.55 & 0.208 \\ 17 & 1.0303 & 1.0293 & 0.43 & 0.004 & 0.566 & 0 & 0.104 & 0.134 & 0.564 & 0.198 \\ 18 & 0.9925 & 1.0204 & 0.425 & 0.004 & 0.571 & 0 & 0.095 & 0.142 & 0.546 & 0.217 \\ 19 & 0.9979 & 0.9864 & 0.416 & 0.004 & 0.58 & 0 & 0.086 & 0.147 & 0.541 & 0.226 \\ 20 & 1.0238 & 1.0061 & 0.4 & 0.009 & 0.591 & 0 & 0.066 & 0.164 & 0.516 & 0.254 \\ 21 & 1.0232 & 0.9875 & 0.397 & 0.008 & 0.595 & 0 & 0.058 & 0.168 & 0.521 & 0.253 \\ 22 & 1.0495 & 1.0034 & 0.409 & 0.005 & 0.586 & 0 & 0.064 & 0.158 & 0.529 & 0.249 \\ 23 & 0.9784 & 1.0219 & 0.445 & 0.004 & 0.551 & 0 & 0.076 & 0.154 & 0.555 & 0.215 \\ 24 & 0.9945 & 0.9506 & 0.501 & 0.002 & 0.497 & 0 & 0.095 & 0.126 & 0.595 & 0.184 \\ & 1.0378 & 1.0067 & 0.479 & 0.003 & 0.518 & 0 & 0.092 & 0.122 & 0.59 & 0.196 \\ 16 & 1.0098 & 0.516 & 0.001 & 0.483 & 0 & 0.116 & 0.121 & 0.605 & 0.158\end{array}$




$\begin{array}{lllllllllll}27 & 0.9632 & 0.9710 & 0.562 & 0.001 & 0.437 & 0 & 0.122 & 0.106 & 0.627 & 0.145 \\ 28 & 0.9811 & 0.9968 & 0.592 & 0.001 & 0.407 & 0 & 0.144 & 0.095 & 0.645 & 0.116 \\ 29 & 1.0420 & 1.0496 & 0.628 & 0 & 0.372 & 0 & 0.158 & 0.084 & 0.65 & 0.108 \\ 30 & 1.0242 & 1.0187 & 0.627 & 0 & 0.373 & 0 & 0.164 & 0.092 & 0.643 & 0.101 \\ 31 & 1.0037 & 1.0187 & 0.633 & 0 & 0.367 & 0 & 0.17 & 0.087 & 0.636 & 0.107 \\ 32 & 1.0083 & 1.0544 & 0.635 & 0 & 0.365 & 0 & 0.163 & 0.089 & 0.644 & 0.104\end{array}$

\subsection{Non-omniscient agents}

We now turn to non-omniscient agents. Sizes of step are again 0.1 on both variables throughout the sample spaces $0 \leq u, p i \leq 1$, and the averages of 15 realizations of games are represented in Figures 9.

Figure 9a: Non-omniscient agents who choose $C$

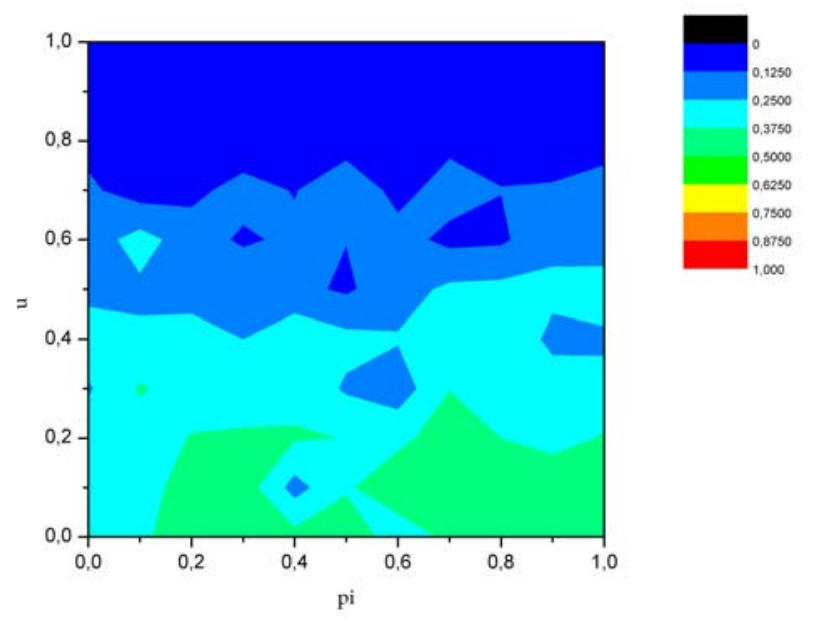

Figure 9b: Non-omniscient agents who choose $C p$ 


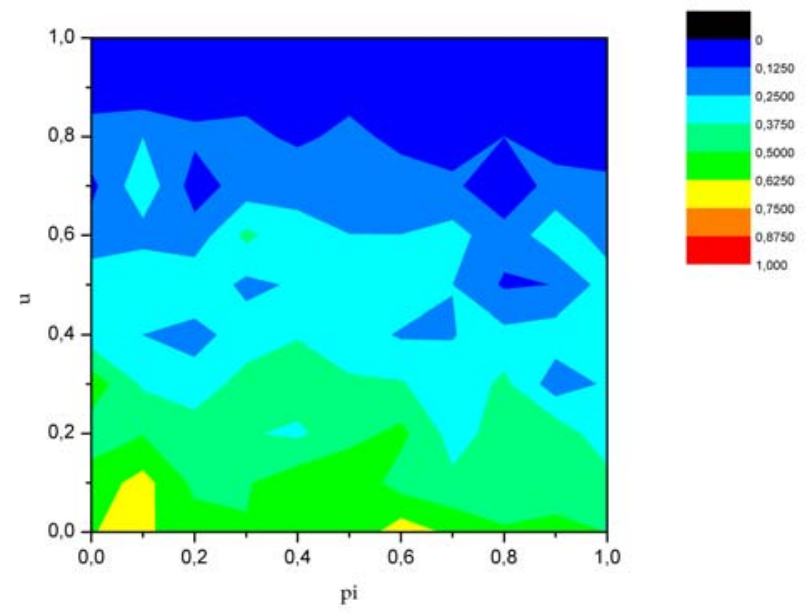

Figure 9c: Non-omniscient agents who choose $C S p$

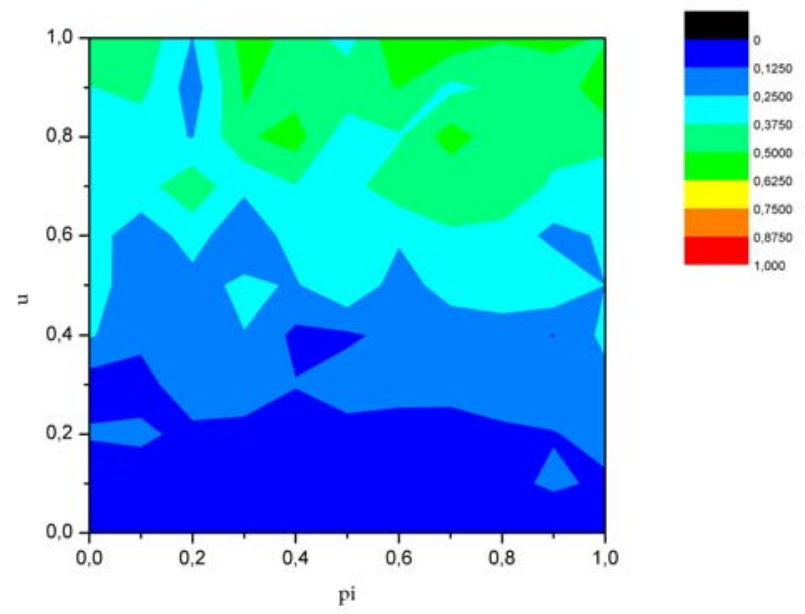

Figure 9d: Non-omniscient agents who choose $C S$

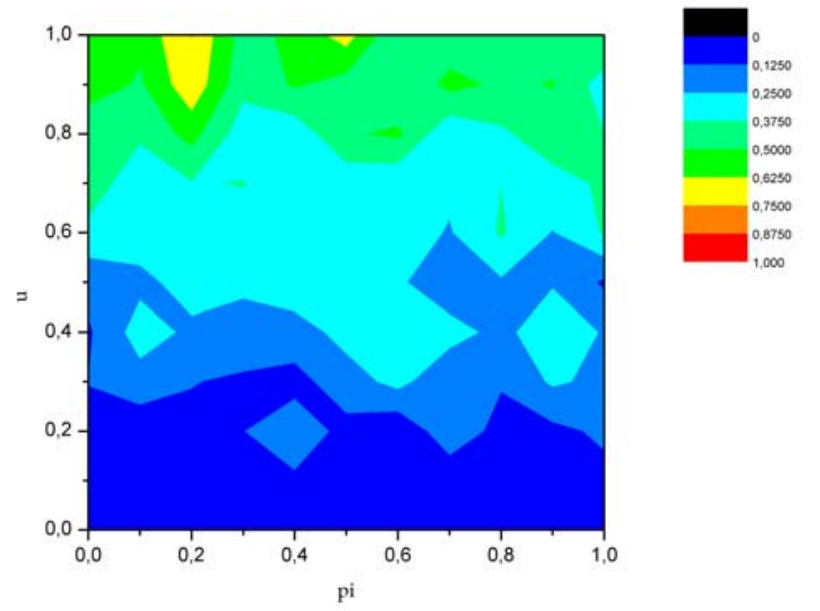


Comparing the games with non-omniscient agents to that with omniscient agents, we see that the level of omniscience of agents plays very significant role in their decision-making. Contrary to the games with omniscient agents, in the nonomniscient environment, no strategy is dominant in the average of 15 realizations of games. Now the relevant factor is no longer the return of stocks, but initial preferences of agents, while on average agents somehow split the strategies they opt for.

Figure 10a: Non-omniscient agents under shock who choose $C$

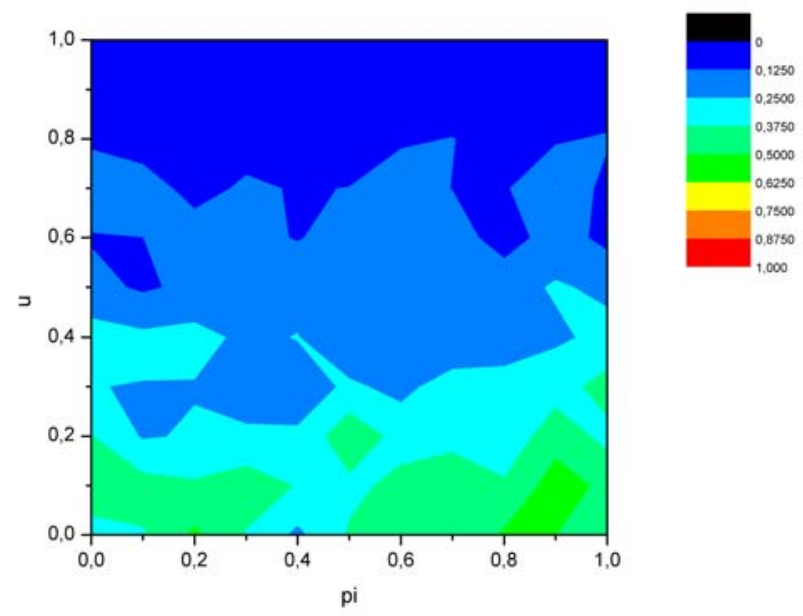

Figure 10b: Non-omniscient agents under shock who choose $C p$
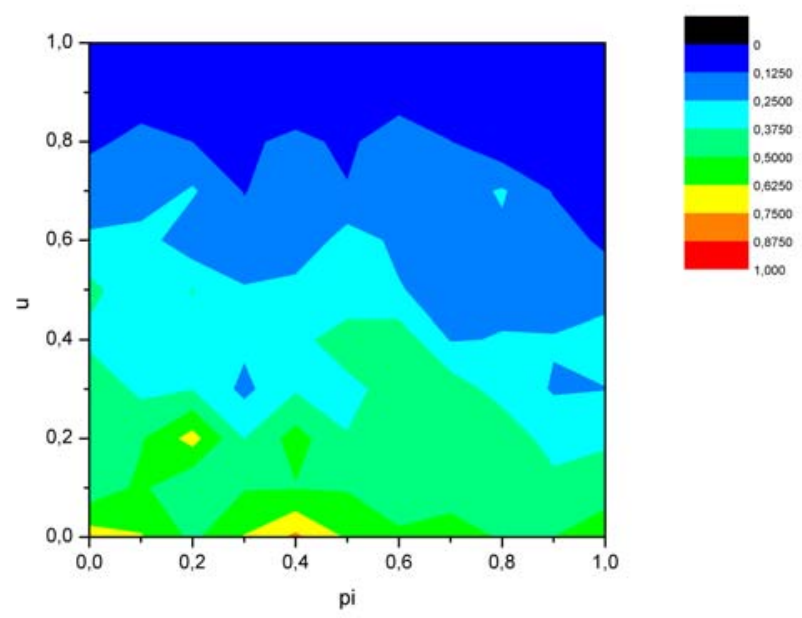
Figure 10c: Non-omniscient agents under shock who choose CSp
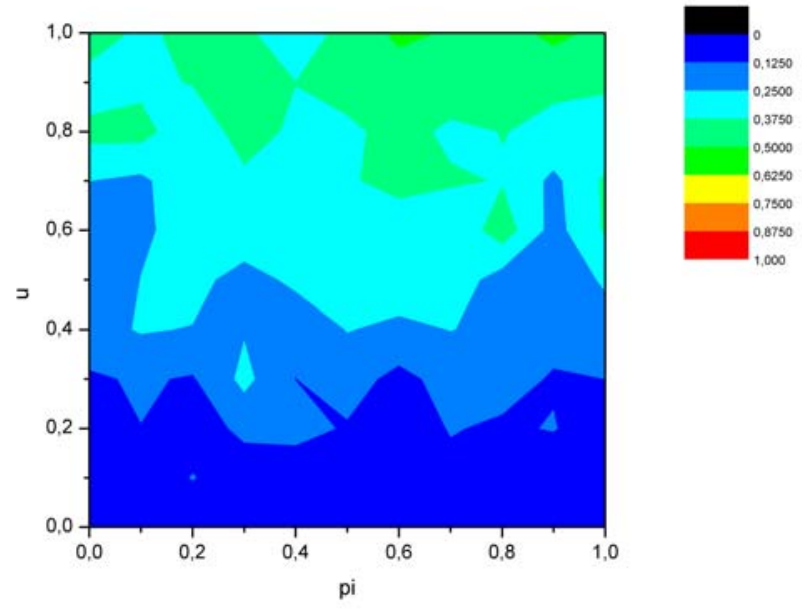

Figure 10d: Non-omniscient agents under shock who choose $C S$
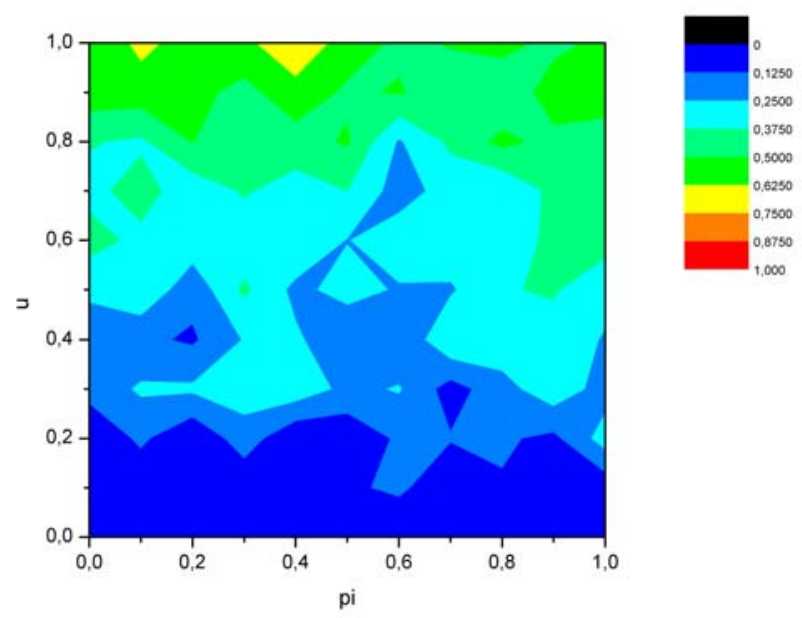

Figures 10 represent the game with included shock. Comparing the two figures of non-omniscient agents, we see that the introduction of a shock does not have a significant effect, as non-omniscient agents do not perceive it. For the details, we go to the individual games.

$$
u=0.5
$$


Again, groups of agents preferring each stock are in the start of equal size, thus $u=0.5$, and are changing in time, while $p i=0.3$ is constant throughout the game. Figures $11 \mathrm{a}, \mathrm{b}$ presents results of the game without a shock, while Figures $12 \mathrm{a}, \mathrm{b}$ presents results of a game with included shock of 500 bps on Citigroup stock in $t=2$.

Figure 11a: Game with non-omniscient agents

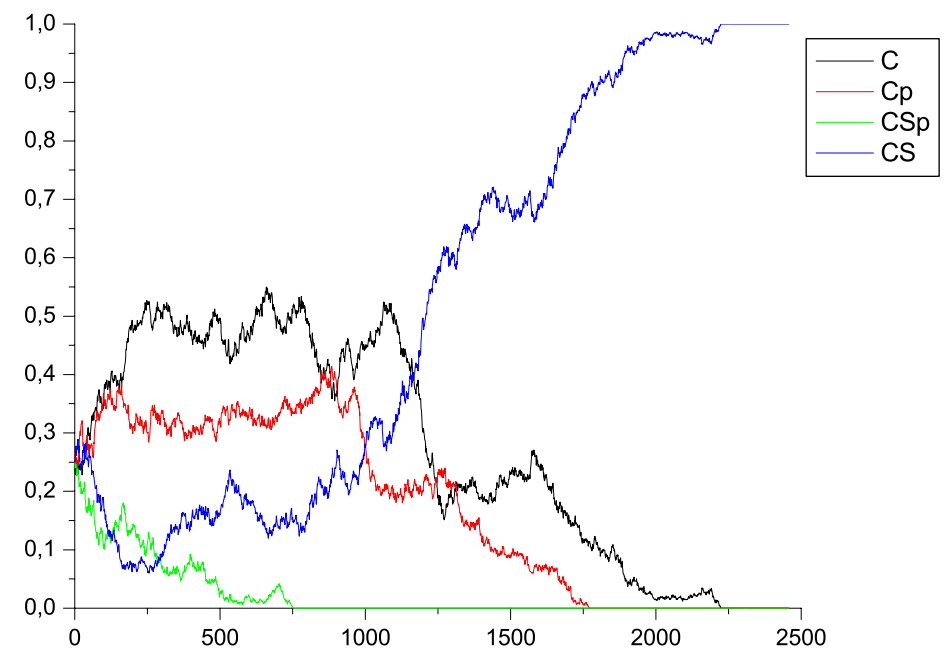

Figure 11b: Game with non-omniscient agents

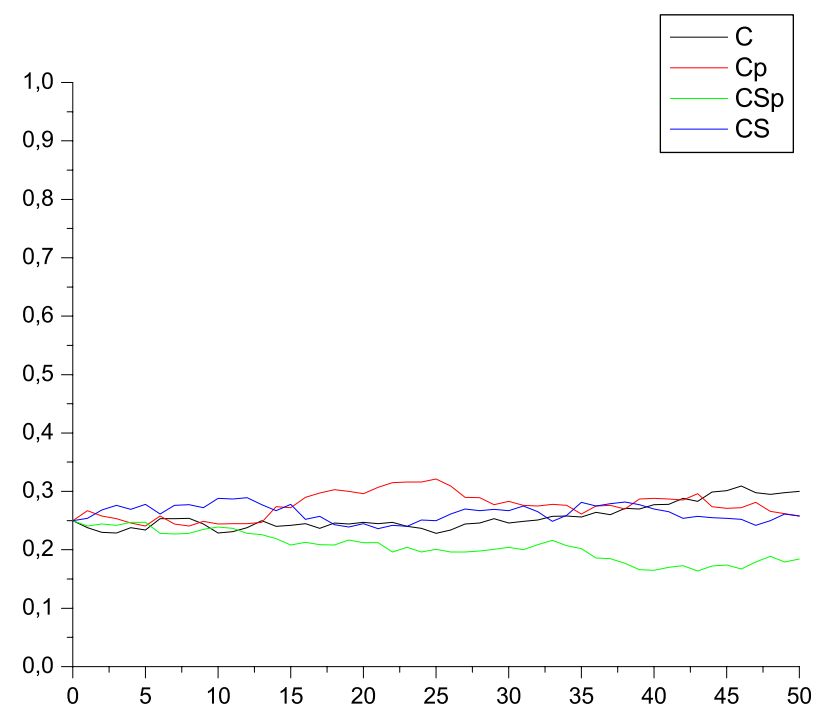


Figures show that non-omniscient agents have quite different patterns of decisionmaking than omniscient agents do.

Figure 12a: Game with a shock

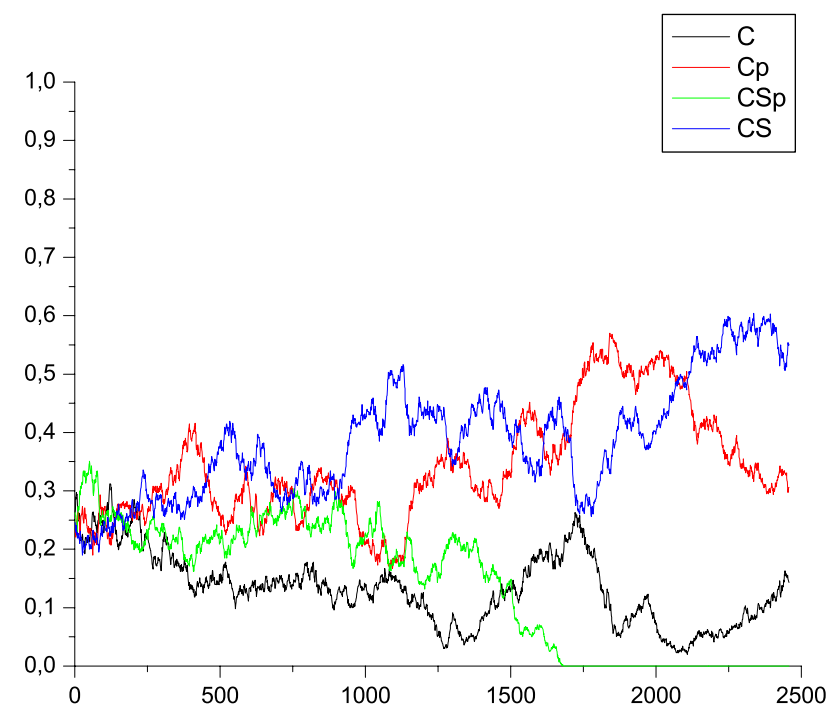

Figure 12b: Game with a shock

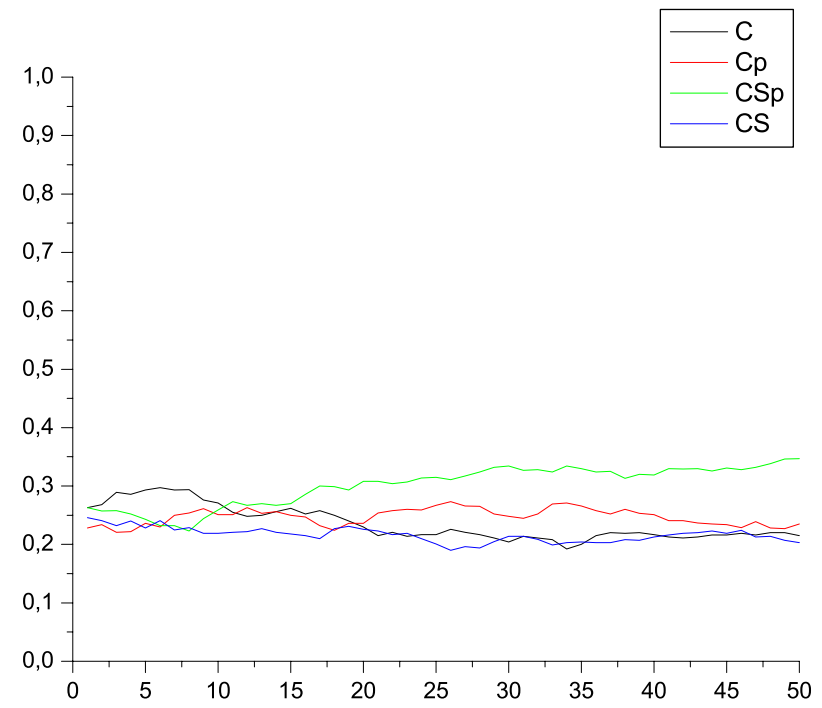

When comparing the two figures above, we see that a shock does not have an influence on the decision-making, as it was the case in the games of omniscient 
agents. Table 3 represents a comparison of developments of the two games in some early stages.

Table 3: Games with no shock and with a shock

$\begin{array}{ccccccccccc}\mathrm{t} & \mathrm{Cr} & \mathrm{CSr} & \mathrm{C} & \mathrm{Cp} & \mathrm{CSp} & \mathrm{CS} & \mathrm{C} \_\mathrm{s} & \mathrm{Cp} \_ \text {CSp_s } & \mathrm{CS} \_\mathrm{s} \\ 1 & 0.9842 & 0.9679 & 0.25 & 0.25 & 0.25 & 0.25 & 0.263 & 0.228 & 0.263 & 0.246 \\ 2 & \mathbf{1 . 0 3 1 7} & 1.0032 & 0.238 & 0.267 & 0.241 & 0.254 & 0.268 & 0.234 & 0.257 & 0.241 \\ 3 & 1.0420 & 0.9968 & 0.23 & 0.258 & 0.244 & 0.268 & 0.289 & 0.221 & 0.258 & 0.232 \\ 4 & 0.9731 & 1.0132 & 0.229 & 0.253 & 0.242 & 0.276 & 0.286 & 0.222 & 0.252 & 0.24 \\ 5 & 1.0313 & 1.0099 & 0.238 & 0.246 & 0.247 & 0.269 & 0.293 & 0.236 & 0.243 & 0.228 \\ 6 & 1.0098 & 1.0227 & 0.234 & 0.241 & 0.247 & 0.278 & 0.297 & 0.23 & 0.232 & 0.241 \\ 7 & 0.9725 & 1.0157 & 0.253 & 0.258 & 0.228 & 0.261 & 0.293 & 0.25 & 0.232 & 0.225 \\ 8 & 0.9733 & 0.9812 & 0.253 & 0.244 & 0.227 & 0.276 & 0.294 & 0.254 & 0.223 & 0.229 \\ 9 & 1.0253 & 0.9938 & 0.254 & 0.241 & 0.228 & 0.277 & 0.276 & 0.261 & 0.244 & 0.219 \\ 10 & 0.9769 & 0.9935 & 0.244 & 0.249 & 0.235 & 0.272 & 0.271 & 0.251 & 0.259 & 0.219 \\ 11 & 0.9952 & 0.9937 & 0.229 & 0.244 & 0.239 & 0.288 & 0.255 & 0.251 & 0.273 & 0.221 \\ 12 & 0.9930 & 0.9934 & 0.231 & 0.245 & 0.237 & 0.287 & 0.248 & 0.263 & 0.267 & 0.222 \\ 13 & 0.9641 & 0.9807 & 0.238 & 0.245 & 0.228 & 0.289 & 0.25 & 0.253 & 0.27 & 0.227 \\ 14 & 1.0350 & 1.0065 & 0.25 & 0.247 & 0.226 & 0.277 & 0.256 & 0.256 & 0.267 & 0.221 \\ 15 & 1.0235 & 1.0263 & 0.24 & 0.274 & 0.219 & 0.267 & 0.262 & 0.25 & 0.27 & 0.218 \\ 16 & 0.9675 & 0.9840 & 0.242 & 0.272 & 0.208 & 0.278 & 0.252 & 0.247 & 0.286 & 0.215 \\ 17 & 1.0303 & 1.0293 & 0.245 & 0.29 & 0.213 & 0.252 & 0.258 & 0.232 & 0.3 & 0.21 \\ 18 & 0.9925 & 1.0204 & 0.237 & 0.297 & 0.209 & 0.257 & 0.25 & 0.224 & 0.299 & 0.227 \\ 19 & 0.9979 & 0.9864 & 0.246 & 0.303 & 0.208 & 0.243 & 0.24 & 0.236 & 0.293 & 0.231 \\ 20 & 1.0238 & 1.0061 & 0.244 & 0.3 & 0.217 & 0.239 & 0.23 & 0.236 & 0.308 & 0.226 \\ 21 & 1.0232 & 0.9875 & 0.247 & 0.296 & 0.212 & 0.245 & 0.215 & 0.254 & 0.308 & 0.223 \\ 22 & 1.0495 & 1.0034 & 0.245 & 0.307 & 0.212 & 0.236 & 0.221 & 0.258 & 0.304 & 0.217 \\ 23 & 0.9784 & 1.0219 & 0.247 & 0.315 & 0.196 & 0.242 & 0.214 & 0.26 & 0.307 & 0.219 \\ 24 & 0.9945 & 0.9506 & 0.24 & 0.316 & 0.204 & 0.24 & 0.217 & 0.259 & 0.314 & 0.21 \\ 25 & 1.0378 & 1.0067 & 0.237 & 0.316 & 0.196 & 0.251 & 0.217 & 0.267 & 0.315 & 0.201 \\ 26 & 1.0423 & 1.0098 & 0.228 & 0.321 & 0.201 & 0.25 & 0.226 & 0.273 & 0.311 & 0.19 \\ 27 & 0.9632 & 0.9710 & 0.234 & 0.309 & 0.196 & 0.261 & 0.221 & 0.266 & 0.317 & 0.196\end{array}$




$\begin{array}{lllllllllll}28 & 0.9811 & 0.9968 & 0.244 & 0.29 & 0.196 & 0.27 & 0.217 & 0.265 & 0.324 & 0.194 \\ 29 & 1.0420 & 1.0496 & 0.246 & 0.289 & 0.198 & 0.267 & 0.211 & 0.252 & 0.332 & 0.205 \\ 30 & 1.0242 & 1.0187 & 0.253 & 0.277 & 0.201 & 0.269 & 0.204 & 0.248 & 0.334 & 0.214 \\ 31 & 1.0037 & 1.0187 & 0.246 & 0.283 & 0.204 & 0.267 & 0.214 & 0.245 & 0.327 & 0.214 \\ 32 & 1.0083 & 1.0544 & 0.249 & 0.276 & 0.2 & 0.275 & 0.211 & 0.252 & 0.328 & 0.209\end{array}$

$$
u=0.8
$$

Finally, we increase the initial share of agents preferring dominated share of CreditSuisse to $u=0.8$. A game without a shock is plotted in Figures 13a, b, and shock is included in Figures $14 \mathrm{a}, \mathrm{b}$. Table 4 represents a comparison of developments of the two games in some early stages.

Figure 13a: Game with non-omniscient agents

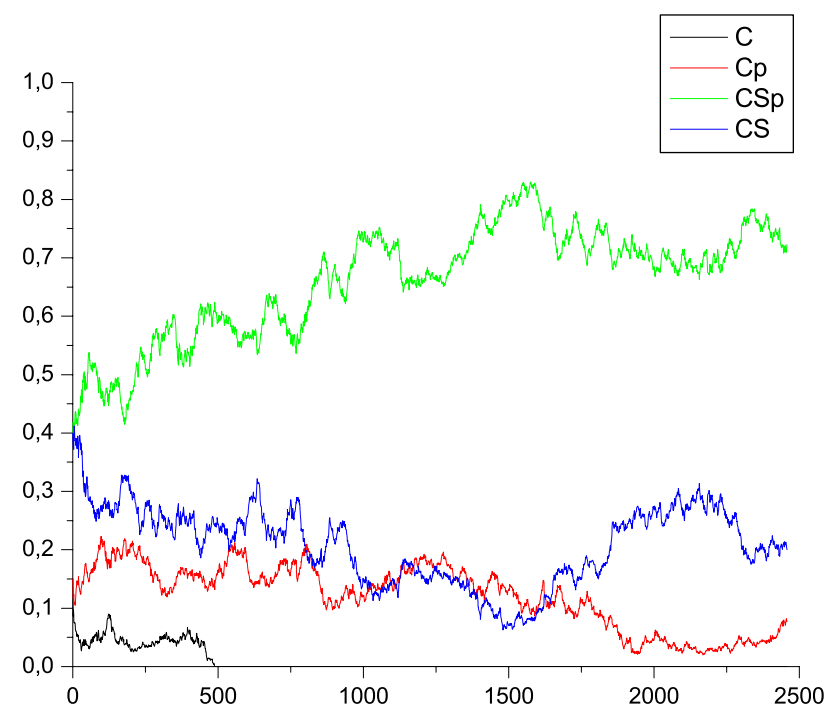

Figure 13b: Game with non-omniscient agents 


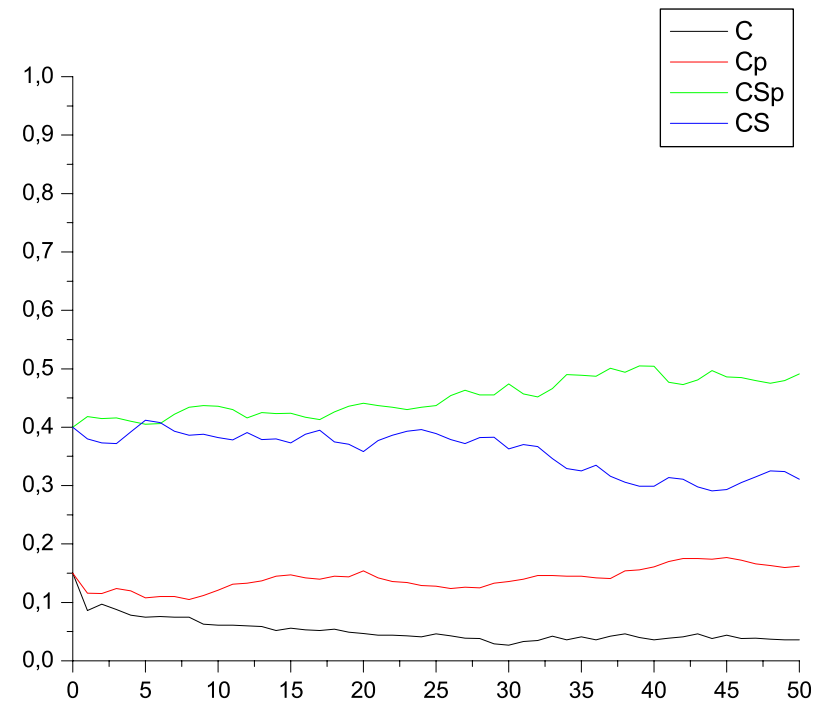

Figure 14a: Game with a shock

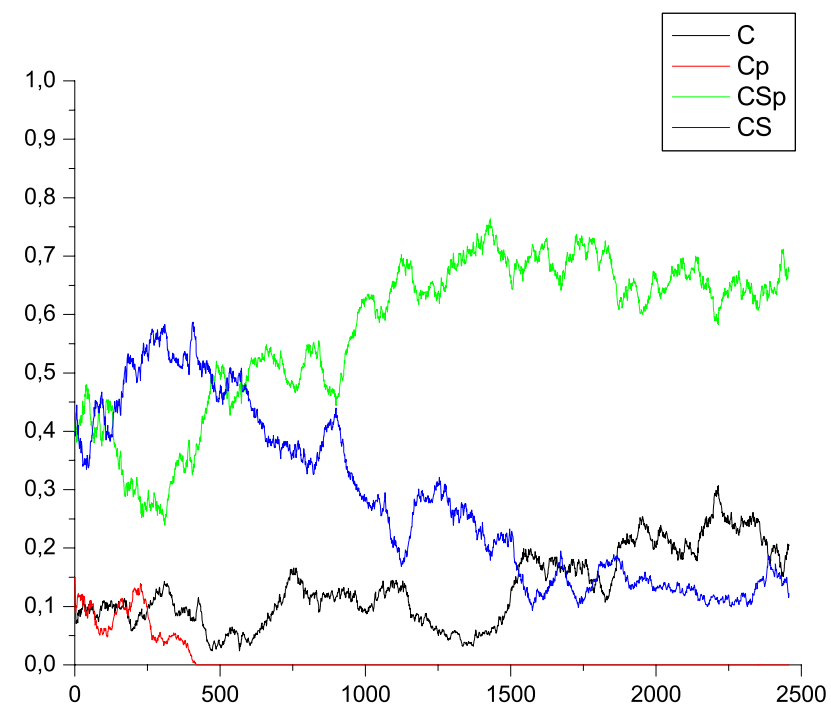

Figure 14b: Game with a shock 


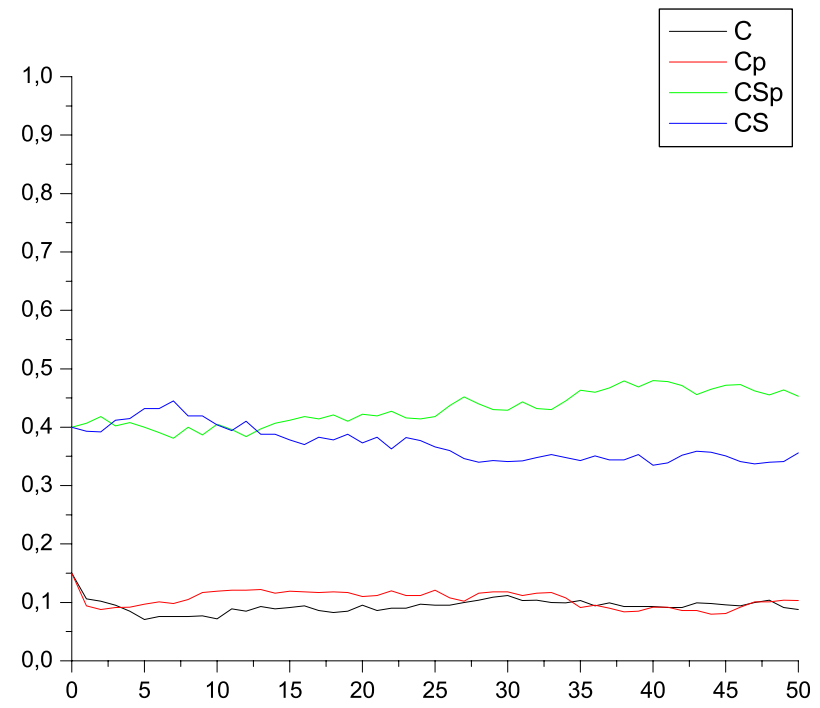

Table 4: Games with no shock and with a shock

$\begin{array}{ccccccccccc}\mathrm{t} & \mathrm{Cr} & \mathrm{CSr} & \mathrm{C} & \mathrm{Cp} & \mathrm{CSp} & \mathrm{CS} & \mathrm{C} \_\mathrm{s} & \mathrm{Cp} \_ \text {s } & \text { CSp_s } & \text { CS_s } \\ 1 & 0.9842 & 0.9679 & 0.15 & 0.15 & 0.4 & 0.4 & 0.15 & 0.15 & 0.4 & 0.4 \\ 2 & \mathbf{1 . 0 3 1 7} & 1.0032 & 0.086 & 0.116 & 0.418 & 0.38 & 0.106 & 0.094 & 0.407 & 0.393 \\ 3 & 1.0420 & 0.9968 & 0.097 & 0.115 & 0.415 & 0.373 & 0.102 & 0.088 & 0.418 & 0.392 \\ 4 & 0.9731 & 1.0132 & 0.088 & 0.124 & 0.416 & 0.372 & 0.095 & 0.091 & 0.402 & 0.412 \\ 5 & 1.0313 & 1.0099 & 0.078 & 0.12 & 0.41 & 0.392 & 0.085 & 0.092 & 0.408 & 0.415 \\ 6 & 1.0098 & 1.0227 & 0.075 & 0.108 & 0.405 & 0.412 & 0.071 & 0.097 & 0.4 & 0.432 \\ 7 & 0.9725 & 1.0157 & 0.076 & 0.11 & 0.406 & 0.408 & 0.076 & 0.101 & 0.391 & 0.432 \\ 8 & 0.9733 & 0.9812 & 0.075 & 0.11 & 0.422 & 0.393 & 0.076 & 0.098 & 0.381 & 0.445 \\ 9 & 1.0253 & 0.9938 & 0.075 & 0.105 & 0.434 & 0.386 & 0.076 & 0.105 & 0.4 & 0.419 \\ 10 & 0.9769 & 0.9935 & 0.063 & 0.112 & 0.437 & 0.388 & 0.077 & 0.117 & 0.387 & 0.419 \\ 11 & 0.9952 & 0.9937 & 0.061 & 0.121 & 0.436 & 0.382 & 0.072 & 0.119 & 0.405 & 0.404 \\ 12 & 0.9930 & 0.9934 & 0.061 & 0.131 & 0.43 & 0.378 & 0.089 & 0.121 & 0.396 & 0.394 \\ 13 & 0.9641 & 0.9807 & 0.06 & 0.133 & 0.416 & 0.391 & 0.085 & 0.121 & 0.384 & 0.41 \\ 14 & 1.0350 & 1.0065 & 0.059 & 0.137 & 0.425 & 0.379 & 0.093 & 0.122 & 0.397 & 0.388 \\ 15 & 1.0235 & 1.0263 & 0.052 & 0.145 & 0.423 & 0.38 & 0.089 & 0.116 & 0.407 & 0.388 \\ 16 & 0.9675 & 0.9840 & 0.056 & 0.147 & 0.424 & 0.373 & 0.091 & 0.119 & 0.412 & 0.378 \\ 17 & 1.0303 & 1.0293 & 0.053 & 0.142 & 0.417 & 0.388 & 0.094 & 0.118 & 0.418 & 0.37 \\ 18 & 0.9925 & 1.0204 & 0.052 & 0.14 & 0.413 & 0.395 & 0.086 & 0.117 & 0.414 & 0.383\end{array}$




$\begin{array}{ccccccccccc}19 & 0.9979 & 0.9864 & 0.054 & 0.145 & 0.426 & 0.375 & 0.083 & 0.118 & 0.421 & 0.378 \\ 20 & 1.0238 & 1.0061 & 0.049 & 0.144 & 0.436 & 0.371 & 0.085 & 0.117 & 0.41 & 0.388 \\ 21 & 1.0232 & 0.9875 & 0.047 & 0.154 & 0.441 & 0.358 & 0.095 & 0.11 & 0.422 & 0.373 \\ 22 & 1.0495 & 1.0034 & 0.044 & 0.142 & 0.437 & 0.377 & 0.086 & 0.112 & 0.419 & 0.383 \\ 23 & 0.9784 & 1.0219 & 0.044 & 0.136 & 0.434 & 0.386 & 0.09 & 0.12 & 0.427 & 0.363 \\ 24 & 0.9945 & 0.9506 & 0.043 & 0.134 & 0.43 & 0.393 & 0.09 & 0.112 & 0.416 & 0.382 \\ 25 & 1.0378 & 1.0067 & 0.041 & 0.129 & 0.434 & 0.396 & 0.097 & 0.112 & 0.414 & 0.377 \\ 26 & 1.0423 & 1.0098 & 0.046 & 0.128 & 0.437 & 0.389 & 0.095 & 0.121 & 0.418 & 0.366 \\ 27 & 0.9632 & 0.9710 & 0.043 & 0.124 & 0.454 & 0.379 & 0.095 & 0.108 & 0.437 & 0.36 \\ 28 & 0.9811 & 0.9968 & 0.039 & 0.126 & 0.463 & 0.372 & 0.1 & 0.102 & 0.452 & 0.346 \\ 29 & 1.0420 & 1.0496 & 0.038 & 0.125 & 0.455 & 0.382 & 0.104 & 0.116 & 0.44 & 0.34 \\ 30 & 1.0242 & 1.0187 & 0.029 & 0.133 & 0.455 & 0.383 & 0.109 & 0.118 & 0.43 & 0.343 \\ 31 & 1.0037 & 1.0187 & 0.027 & 0.136 & 0.474 & 0.363 & 0.112 & 0.118 & 0.429 & 0.341 \\ 32 & 1.0083 & 1.0544 & 0.033 & 0.14 & 0.457 & 0.37 & 0.103 & 0.112 & 0.443 & 0.342\end{array}$

The last figures and the table correspond to the Figure 9 and Figure 10, which demonstrated the behavior of non-omniscient agents. It has been demonstrated that non-omniscient agents are almost immune to one-time shocks, for which they do not alter their behavior significantly.

\section{Concluding remarks}

It has been demonstrated that effects that shocks have on decision-making of agents on financial markets largely depend on the levels of omniscience of agents. Omniscient agents very quickly respond on the market conditions with a one timeperiod lag, while non-omniscient agents do not. Despite omniscient agents overcome it, introduction of a shock has huge long-run consequences, as it changes the inter-game conditions, leading us to a butterfly-effect in financial decision-making.

It has also been proved that information channels, i.e. positions of agents in social networks, are of a decisive importance in the process of decision-making of 
agents, which is true especially in the environment of omniscient agents. This leads omniscient agents to far more frequently behave in herds than nonomniscient agents do. On the short run, especially when stock returns are wide apart, making a portfolio is very frequent solution for agents that face decreasing returns on stocks they possess.

\section{REFERENCES}

1. Abreu, D., Brunnermeier, M. (2003). Bubbles and Crashes. Econometrica, 71(1), 173-204.

2. Bikhchandani, S., Hirshleifer, D., Welch I. (1998). Learning from the Behavior of Others: Conformity, Fads, and Information Cascades. Journal of Economic Perspectives, 12(3), 151-170.

3. Cont, R., Bouchaud, J-P. (2000). Herd Behavior and Aggregate Fluctuations in Financial Markets. Macroeconomic Dynamics, 4(2), 170-197.

4. Hayek, F.A. (1945). The Use of Knowledge in Society. American Economic Review, 35(4), 519-530.

5. Hirshleifer, D. (2002). Investor Psychology and Asset Pricing. Journal of Finance, 56(4), 1533-1597.

6. Kahneman, D., Tversky A. (1979). Prospect Theory: An Analysis of Decision under Risk. Econometrica, 47(2), 263-291.

7. Lux, T. (1995). Herd Behavior, Bubbles, and Crashes. Economic Journal, 105(431), 881-896.

8. Mises, L. (1996). Human Action: A Treatise on Economics. Fourth Edition. San Francisco: Fox and Wilkes.

9. Rand, A. (1964). The Virtue of Selfishness. New York: Signet.

10. Rubinstein, A. (1998). Modeling Bounded Rationality. Cambridge: MIT Press.

11. Shiller, R. (2002). Irrational Exuberance. Princeton: Princeton University Press.

12. Szabó, G., Tőke C. (1998). Evolutionary Prisoner's Dilemma Game on a Square Lattice. Physical Review E, 58(1), 69-73.

13. Wasserman, S., Faust K. (1998). Social Network Analysis: Methods and Applications. Cambridge: Cambridge University Press.

14. Watts, D., Strogatz S. (1998). Collective Dynamics of Small World Networks. Nature, 393(4), 440-442.

Figures legend

$C$, plotted with black line, represents the share of agents who prefer Citigroup stocks and play pure strategies, $C p$, plotted with red line, represents the share of agents who prefer Citigroup stocks and opt for a portfolio. $C S$, plotted with green line, and $C S p$, plotted with blue line, represent shares of agents who prefer CreditSuisse stocks and opt for pure strategies or portfolio.

Color-palettes in Figures 3, 4, 9, and 10 represent shares of agents who opt for a particular strategy in last time-interval. 